\title{
What Can We Learn from Ambient Ionization Techniques?
}

\author{
Huanwen Chen, ${ }^{\mathrm{b}}$ Gerardo Gamez, ${ }^{\mathrm{a}, *}$ and Renato Zenobi ${ }^{\mathrm{a}}$ \\ ${ }^{a}$ Department of Chemistry and Applied Biosciences, ETH Zürich, Zürich, Switzerland \\ ${ }^{b}$ Applied Chemistry Department, East China Institute of Technology, Fuzhou, China
}

\begin{abstract}
Ambient mass spectrometry-mass spectrometric analysis with no or minimal effort for sample preparation-has experienced a very rapid development during the last 5 years, with many different methods now available for ionization. Here, we review its range of applications, the hurdles encountered for its quantitative use, and the proposed mechanisms for ion formation. Clearly, more effort needs to be put into investigation of matrix effects, into defining representative sampling of heterogeneous materials, and into understanding and controlling the underlying ionization mechanisms. Finally, we propose a concept to reduce the number of different acronyms describing very similar embodiments of ambient mass spectrometry. (J Am Soc Mass Spectrom 2009, 20, 1947-1963) (c) 2009 American Society for Mass Spectrometry
\end{abstract}

$\mathrm{A}$ mbient mass spectrometry is defined as mass spectrometric analysis with no or minimal effort for sample preparation, using direct sampling and ionization at ambient conditions [1]. Note that this is different from atmospheric pressure ionization: for example, for atmospheric pressure MALDI-MS, the sample still needs to be mixed and co-crystallized with matrix, or for ESI-MS, another very popular atmospheric pressure ionization method, dissolution of the sample and, often, desalting steps are necessary. Many MS specialists expected their field to "plateau at a high level" after the introduction and successful commercialization of MALDI and ESI, and the recognition of these achievements with the chemistry Nobel prize in 2002. However, perhaps fueled by the availability of excellent and very sensitive instrumentation and/or by the fact that the MS field has attracted many brilliant minds, the surge continued and is still continuing. In the last years, there has been a flurry of developments, most notably the introduction of sources for ambient mass spectrometry, including desorption by electrospray ionization (DESI) [2], direct analysis in real time (DART) [3], extractive electrospray ionization (EESI) [4, 5], secondary electrospray ionization (SESI) [6, 7], and many combinations of desorption with postionization methods working at atmospheric pressure (for a review, see [8]). No less than 25 different ambient surface desorption/postionization methods for the analysis of medium to low volatility compounds have been described in the literature in the last few years! Another fascinat-

Address reprint requests to Dr. R. Zenobi, Department of Chemistry and Applied Biosciences, ETH Zürich, CH-8093 Zürich, Switzerland. E-mail: zenobi@org.chem.ethz.ch

* Current address: Department 128, EMPA-Swiss Federal Laboratories for Materials Testing and Research, Feuerwerkstr. 39, CH-3602 Thun, Switzerland. ing development that took place in parallel was the development of portable or miniaturized mass spectrometers [9-14]. An entire issue of this journal [JASMS 2008, 19(10)] has been devoted to this topic under the heading "Harsh Environment Mass Spectrometry" [12, 13, 15-22]. Although all of the field-portable mass spectrometers available nowadays are less powerful in terms of sensitivity, mass range, and mass resolving power than their laboratory-based counterparts, the vision is clearly to combine suitable atmospheric pressure sources with portable mass spectrometers to run analyses in subway systems, airports, at sports events, in restaurants, supermarkets, wholesale markets, and perhaps in the future even in the average home.

\section{Samples Accessible for Analysis by Ambient Ionization Techniques}

Ambient mass spectrometry has opened the door for detection of trace chemicals in complex matrices, using minimal or no sample preparation. The samples usually maintain their original chemical/physical/biological states without external interference before ionization [1, 23]. Biological [24-27], pharmaceutical [4, 28-30], environmental [31-34], food [35-38], and forensic samples [39-42] have been successfully examined by ambient mass spectrometry; typical examples of such analyses have been summarized in recent reviews [1, 8, 43, 44]. Although the chemical composition and origins of samples can change dramatically in different studies, solid surfaces, solutions, and liquid mixtures are usually the states to be characterized by ambient mass spectrometry. Solid surfaces are classic samples for analysis by DESI [2] and similar techniques such as DART [3], desorption-atmospheric pressure chemi- 
cal ionization (DAPCI) $[45,46]$, dielectric barrier discharge ionization (DBDI) [47], and ionization by a lowtemperature plasma (LTP) [48]. Theoretically, there are no restrictions with respects to sample geometry, size, and weight. In reality, however, these parameters are limited by the source design, which can vary considerably for different techniques.

Ion production relies heavily on the molecular interaction/charge-transfer process occurring on the sample surface (discussed in detail later in the Mechanism section). The primary ions (e.g., protonated reagent species) are generated using electrospray ionization (e.g., DESI, SESI, EESI), a corona discharge (e.g., DAPCI, DBDI), or a plasma torch (e.g., LTP). Metastable atoms created using discharge techniques (e.g., glowto-corona discharge) $[49,50]$ are generally believed to be responsible for ionization in DART [3], being the species that initiate ion-molecule reactions and that trigger charge and proton transfer reactions. For most techniques, the reagent ion beam is restricted within a diameter less than $0.1 \mathrm{~cm}$. Thus, the samples surface area is no more than $1 \mathrm{~cm}^{2}$ in most cases. A large sampling area is desirable for many applications such as high throughput screening. A sampling spot larger than $5 \mathrm{~cm}^{2}$ has been demonstrated for cocaine detection using LTP [48]. Using a reasonably low power, however, it might be difficult to maintain stable plasma at low temperature to cover a large area. For a plasma torch of a big diameter, the temperature at the center of a plasma beam can be much higher than that at the edges because of the heat accumulation inside the large plasma beam. In such a case, heat sensitive surfaces may be damaged and release pyrolysis products, resulting in extra efforts required for interpreting the spectral data. Large area $\left(2.5 \mathrm{~cm}^{2}\right)$ analysis has been demonstrated using DESI [51], without pyrolysis effect. However, directly analyzing large surface areas is still challenging for many ambient surface ionization techniques [51].

On the other hand, by utilizing a particularly small diameter reagent ion beam, applications have been demonstrated to obtain spatially resolved chemical information with ambient mass spectrometry [41, 52-54]. By moving the sample, two-dimensional information is available, allowing sensitive imaging by ambient mass spectrometry. To date, DESI is the most successful technique for such imaging applications $[23,28,52]$. The spatial resolution that can be reached by DESI-MS is about $250 \mu \mathrm{m}[23,52,55]$, recently has reached $40 \mu \mathrm{m}$ [56]. Further improvements in resolution are imaginable for DESI imaging $[57,58]$. When the diameter of a reagent ion beam is reduced, less sample is interrogated and, thus, the signal intensity is also reduced. Therefore, it is always desirable to enhance the sensitivity of ambient mass spectrometry.

A different issue is highly specific detection in imaging experiments, which can be achieved using tandem MS or $\mathrm{MS}^{\mathrm{n}}$ experiments to exclude false positive signals. A tandem MS method with ionization by DAPCI has been developed to visualize the distribution of melamine in egg samples [59], resulting in a twodimensional molecular image with a spatial resolution ca. $0.06 \mathrm{~mm}^{2}$.

So far, mostly two-dimensional images have been recorded using ambient mass spectrometry. A notable exception is the work in the group of Vertes, in which depth profiling with LAESI was performed [60], a distinct step towards generating three-dimensional molecular images [61] with high sensitivity, specificity, and throughput.

Most ambient ionization techniques are essentially noninvasive for solid surface analysis. For cases where the matrix is dissolved, e.g., by the impinging electrospray droplets in DESI, material loss from the sample is detectable. For example, using methanol/water as the spray solvent, the total mass of a pharmaceutical tablet decreased by about $1 \mathrm{mg}$ after subjecting it to a DESI source for a few minutes $[4,62]$. For other solid surfaces, including paper, clothes, plastics, metal, etc., there is no significant material loss reported using ambient mass spectrometry. This feature renders ambient mass spectrometry ideally suitable to investigate the outermost layer of a solid surface. Chipuk and Brodbelt have introduced a transmission mode DESI source where the electrospray is not deflected off of a surface but instead is transmitted through a mesh that carries the sample [63]. According to these authors, this configuration works well for liquid samples and needs less optimization of angles and distances than standard DESI.

Complex liquid matrices can also be analyzed by techniques such as DESI, DART, and DAPCI etc. once the liquid is dried on a surface. Alternatively, liquid mixtures can be directly analyzed using EESI [64-66] or similar techniques [67]. In EESI, a neutral liquid sample is dispersed into a charged plume formed by electrospraying pure solvent (e.g., an acetic acid/methanol water solution). Analyte molecules undergo interactions and collisions with the charged ESI droplets and become ionized in an ESI-like fashion for further mass spectral analysis. Ion suppression effects by the matrix are drastically reduced, because the matrix is dispersed over a relatively large-volume. This results in a high tolerance of EESI for complex matrices. For example, untreated biological materials such as raw urine or milk can be directly infused to generate constant signal for hours $[66,68,69]$. Another significant merit of EESI is that the sample is isolated from any high voltage and can be located far way from the EESI source. This renders EESI attractive for real-time on-line, and even remote analysis. Theoretically, the distance between the bulk liquid reservoir and the EESI source has no restriction; however, the longer the sample transfer line, the longer the transfer time and, thus, the slower the response is. Our preliminary results showed that a delay in signal response of about $6 \mathrm{~s}$ was observed when a 10-m sample transfer line was used. Of course this delay depends on the flow rate, i.e., it might be reduced when the flow rate is increased. 
For homogeneous liquid solutions, the fraction of the bulk solution, which is sampled for EESI-MS analysis reflects the composition of the whole sample. For heterogeneous liquid mixtures which can also be handled by EESI-MS, the composition might vary with the sampling location [70]. EESI is not intrinsically a tool for surface analysis, because filling the sample transfer line (e.g., a fused silica capillary) requires a few $\mu \mathrm{M}$ liquid sample. However, using a neutral desorption sampling technique, biological sample surfaces $[5,71-74]$ and the surface of a hanging liquid droplet [75] have been successfully investigated by EESI-MS. For the hanging droplet experiment, the data suggests that a volume of liquid, which is probably representative of the bulk sample is liberated using the neutral gas beam [75].

Material can also be liberated from inside a liquid sample [70] by a microjetting mechanism [76, 77]. In this case, liquid droplets representing the molecular composition of the bulk sample are transported by a stream of nitrogen gas into the EESI source $[5,65,66,68,71,75,78$, 79], followed by ionization and detection. As a result, liquids with complex chemical compositions and high viscosities (e.g., serum, honey, edible oils, crude oils, ionic liquids, toothpaste, etc.) can be directly characterized without sample pretreatment. Thus, neutral desorption EESI-MS is able to obtain the molecular information on both volatile and nonvolatile compounds in complex mixtures of high viscosity samples.

\section{Case Study I: Direct Detection of Melamine in Milk by Ambient Ionization MS}

In September 2008, infant formula that was illegally adulterated with melamine led to health problems of thousands of infants in China. This accident received attention from all over the world and, thus, melamine is a currently hot analyte in food quality monitoring. The analytical issues are that milk is a relatively complex matrix, and that detection limits in the high ppb range are required. Several different ionization methods were employed to approach this analytical problem.

The first study was completed using DART in 2007 [80]. Melamine in either liquid or powdered milk samples was extracted using methanol and then dried on the surface of a glass probe, which was positioned directly in the DART ion source. A detection limit of tens of ppbs was achieved. By heating the milk up to $180{ }^{\circ} \mathrm{C}$, Shiea and coworkers detected the melamine ion signal ( $m / z$ 127) with fused-droplet electrospray ionization (FD-ESI) mass spectrometry [81]. The detection limit was lower than $0.05 \mathrm{ppm}$, which is quite good. However, these workers detected the melamine ion signal in almost all the milk samples investigated, even in expressed human breast milk. The same was true for dissolved milk powder from a range of origins; again, the analysis was done by heating the milk followed by FD-ESI MS. Their preliminary conclusion was therefore that heating the milk to $180{ }^{\circ} \mathrm{C}$ might generate mel- amine or another interfering substance. When electrospray laser desorption/ionization (ELDI) was used to detect melamine in milk without sample pretreatment (heating, in this case), the detection limit was 5 ppm, higher than the safety level (2.5 ppm) [82]. Untreated liquid milk can be directly infused into EESI for sensitive analysis [66]. Alternatively, milk can be introduced into an EESI source for quantitative melamine detection [64] using an ultrasonic transducer for sample nebulization (Figure 1). This resulted in a very short analysis time, around $30 \mathrm{~s} /$ sample. For powdered samples, such as wheat gluten and milk powder, a rapid extraction by methanol was performed, and the extract was then directly subjected to ultrasound-assisted EESI-MS, resulting in a limit of detection (LOD) of $200 \sim 300 \mathrm{ppb}$ for melamine in various food samples [64]. Powdered milk samples were also directly analyzed by LTP-MS [38], with an excellent LOD of $6 \mathrm{ppb}$. The time required for analysis was also about $30 \mathrm{~s}$; however, analysis of liquid milk was not demonstrated using LTP-MS. Trace amounts of melamine in powdered/liquid milk [37, 59] and in a slice of a cooked egg [59] can be semiquantitatively detected by using DAPCI-MS. The LOD for melamine was in the low $\mathrm{ppb}$ range when a high desorption temperature $\left(150 \sim 200{ }^{\circ} \mathrm{C}\right)$ was used. The experimental data suggest that melamine strongly binds to proteins in food samples such as milk products and cooked egg white. In such a case, the desorption efficiency must be improved to ensure highly sensitive detection. As demonstrated for melamine detection, the sensitivity was significantly enhanced when a high desorption temperature was used such as in LTP [38] or DAPCI [37, 59].

Melamine is detected in protonated form in all the studies performed using ambient mass spectrometry. Different fragmentation patterns of protonated melamine $(\mathrm{m} / \mathrm{z} 127)$ were observed using different ionization techniques, probably because the total energy deposited onto the product ions were quite different. These differences in the data obtained with DAPCI, ESI, and DESI at different operation conditions were discussed by Yang et al. [37]. The data available showed that plasma based techniques such as LTP and DAPCI deposit more energy than other ESI-based ambient ionization techniques into the protonated melamine molecules. This fact indicates that the predominant chemistry and the physical process differ for each ionization technique, such that ambient mass spectrometry could become a tool to investigate chemistry occurring under ambient conditions.

One also needs to distinguish simple detection of melamine (or isobaric interferences) at $m / z=127$ versus more complex MS experiments for positive identification of melamine. Accurate mass measurements, tandem mass spectrometry experiments, or other confirmatory experiments have been used in some studies to exclude false positives [37, 38, 59, 80] in studies of melamine contamination of milk products. For example, in powdered milk, 5-hydroxymethylfurfural (HMF; 



\section{cone inlet}

(b)

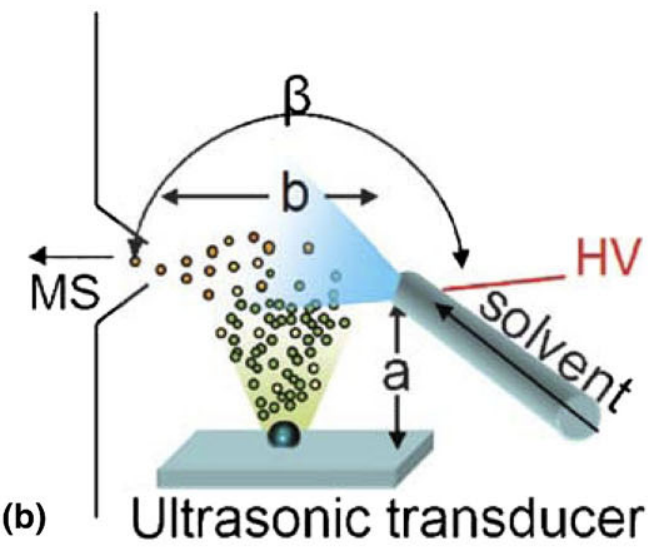

Figure 1. Typical ambient ionization techniques for rapid detection of melamine in milk samples. (a) Schematics of an LTP source; reprinted from [38], with permission. Copyright 2009, Royal Society of Chemistry. (b) Schematic of ultrasound-assisted EESI source; reprinted from [64], with permission. Copyright 2009, Royal Society of Chemistry. (c) Schematics of a DAPCI source; reprinted from [37], with permission. Copyright 2009, American Chemical Society. (d) Molecular structure of melamine.

molecular weight $=126$ ) gives a predominant peak at $\mathrm{m} / \mathrm{z} 127$, which is a typical false positive signal interfering with the detection of melamine in milk products [37, 59]. In tandem mass spectrometry, the dissociation pattern of HMF ions differs from that of protonated melamine [37].

\section{Case Study II: Direct Detection of Explosives on "Real World" Surfaces}

Homeland security and public safety are interesting fields of application for ambient mass spectrometry, especially the rapid detection of explosives $[83,84]$ and of illicit drugs [51, 85]. Basically, every ambient technique has been used to detect explosives on various surfaces. The first application of ambient mass spectrometry to explosives detection was by Cooks and coworkers in early 2005, using DESI [83]. It was shown that DESI, like a trained dog, detects low nanogram amounts of explosives, such as TNT and RDX, on various surfaces without any prior sample treatment [83]. Following this study, a selective ion/molecule reaction was implemented in the DESI process to improve the specificity and sensitivity for explosives detection [86]. This work was cited over 100 times in about 4 years, showing the high impact of ambient MS in the field of explosive detection. DESI has been used for remote explosive detection since the ambient ions can be sampled from several meters away from the ion entrance of the mass spectrometer [87]. The first unambiguous detection of TATP, another popular explosive, which cannot be detected using conventional methods since it contains no nitro group, was also accomplished by DESI [84]. Explosives are nonvolatile compounds with extremely low vapor pressure, and are likely to accumulate on various surfaces. DESI successfully detected explosives on a wide variety of surfaces, such as paper, leather, plastics, metal [86], human skin [88], textiles [89], etc., showing its versatility in this area. Using the classic open-air DESI source, subnanogram quantities of explosives can now be detected. Using a novel geometry-independent DESI source [90], the sensitivity of DESI for explosives detection can be further improved.

A low LOD in the detection of explosive can alternatively be achieved using DAPCI since chemical ionization has a higher ionization efficiency than ESI in most cases. For example, the LODs of most explosives were in the sub-picogram range on various surfaces tested [46, 91]. The difference in sensitivity can be ascribed to the different formation mechanisms of analyte ions by these techniques, convoluted by differences 
in ion transmission from the source to the mass spectrometer. A direct comparison is therefore difficult. Besides DAPCI, many other ambient techniques, such as DBDI [47], LTP [48, 92], DART [93], ELDI [94], SESI [95], and EESI $[72,74]$ etc. have been employed to detect explosives on surfaces or in solution. These techniques provide good analytical performance, similar to that of DESI, particularly in terms of sensitivity and specificity. To date, only DESI [87] and EESI [72] have shown their capabilities for selective ionization and remote analysis, both of which are critical features for mass spectrometric detection of explosives, chemical warfare agents, and for biohazard investigations.

As mentioned above, the chemical and physical processes could differ for different ambient ionization techniques. This was in fact observed in many studies on explosives. For example, TNT (MW 227) was detected as the deprotonated negative ions $(\mathrm{m} / \mathrm{z} 226)$ (Figure 2a) using LTP [48, 92]. More extensively fragmented ions such as $\mathrm{m} / \mathrm{z} 197$ were detected as the most abundant peak (Figure 2c) in the full scan mass spectra recorded using DBDI [47]. On-line single-particle aerosol mass spectrometry (SPAMS) detected deprotonated TNT ions as the base peak [96], with no or low abundance of the radical anions $(m / z 227)$. Both signals of TNT (i.e., $m / z 226$ and 227) (Figure 2b) were detectable using DAPCI [46] and DART [93] as well; the ratio of these two signals varied with the working conditions of the source. In contrast, the radical anion $(\mathrm{m} / \mathrm{z} 227)$ was detected as the base peak of TNT using DESI (Figure 2d), and EESI (Figure 2e). Interestingly, the deprotonated TNT signal $(m / z 226)$ was exclusively observed in SESI (Figure 2f), suggesting that the mechanism of SESI is quite different from DESI or EESI. TNT radical anions were also exclusively observed in single photon ionization mass spectrometry (Figure 2g) [97, 98]. The relative abundance of the various signals in the mass spectra thus depend on how and how much energy is deposited into the ions. These data rationalize that electrospray-based ambient ionization techniques are generally gentler for explosives detection than corona discharge-based techniques.

\section{Standardization: From Concept to Real Life}

A glance at the literature of ambient ionization techniques clearly shows that it is dominated by proof-ofprinciple studies. The burden of promoting such applicability into standardization, however, has not found such a powerful thrust. This requires not only a systematic study of the reliability of qualitative approaches but also a rigorous characterization of quantitative methods. For example, it is one of the main clear advantages of ambient ionization techniques that analysis may be performed without sample preparation. Nevertheless, it is natural that the matrix hosting the analyte of interest should have an effect on the analysis, but systematic studies on matrix effects are rare. In this section we will illustrate the hurdles encountered in quantitative analysis via ambient ionization techniques and some efforts to overcome them.

The use of an internal standard in ambient mass spectrometry was already shown in the first publication on DESI [2]. In a more recent example, Ifa and coworkers reported on the quantitative analysis by DESI of small molecules samples spotted on PTFE surfaces with different roughness [99]. The dependence of the ion signal on the type of substrate onto which the sample is spotted is the first indication that quantitation/monitoring may not be as straightforward as implied. This phenomenon is not only characteristic of DESI; for example, in DAPPI it has been shown that the signal is influenced by the substrate thermal conductivity [100] and it is not far fetched to assume that other techniques relying to some extent on thermal mechanisms for desorption will be subject to the same phenomenon. Ifa et al. used internal standards to correct for differences in spot sizes and drying processes during DESI analysis [99]. They found an inter-day precision of $13 \%$ for 0.01 $\mu \mathrm{M}$ propranolol (better than $7 \%$ for higher concentrations) and an inter-day accuracy better than $\pm 7 \%$. Internal standards, however, should be used with caution. For example, Nyadong et al. showed that the internal standard-to-analyte ratios in DESI tablet analysis have a dependence on the tablet's hardness [101]. Moreover, $\mathrm{Yu}$ et al. found that adding an internal standard to samples in rat plasma matrix did not significantly improve the precision and accuracy of DART analysis [24]. They showed that at $2 \mathrm{ng} / \mathrm{mL}$ benzoylecgonine, triplicate measurements without internal standard yielded $12 \%$ bias with respect to the standard concentration (better than $6 \%$ above $20 \mathrm{ng} /$ $\mathrm{mL}$ ) and $34 \%$ coefficient of variance (better than $12 \%$ above $5 \mathrm{ng} / \mathrm{mL}$ ). In an alternative DESI quantitative approach, Nyadong and coworkers took advantage of competitive reactions between crown ethers (added to the DESI solution) and the analyte (oseltamivir) where the abundance ratio of the formed complexes depends on the amount of analyte present [102].

Since the inception of ambient ionization techniques has been apparent that the sampling geometry can greatly influence the signal intensities. Thus, one aspect that has greatly improved the reproducibility is the use of autosamplers, which maintain parameters such as the source-sample distance and angle as well as the samplemass spectrometer inlet distance and angle constant.

A more subtle issue is that of matrix effects. These may not only arise during desorption, but also in the ionization process. Jackson et al. showed evidence of matrix effects, including suppression, in the analysis of E. coli extracts via DESI [103]. Such interferences in DESI could be alleviated through the use of in situ ambient chemical reactions, such that the specificity and sensitivity of detection is improved [103]. Other ambient ionization techniques are not exempt from matrix effects. Yu et al. studied the effect of different biological 


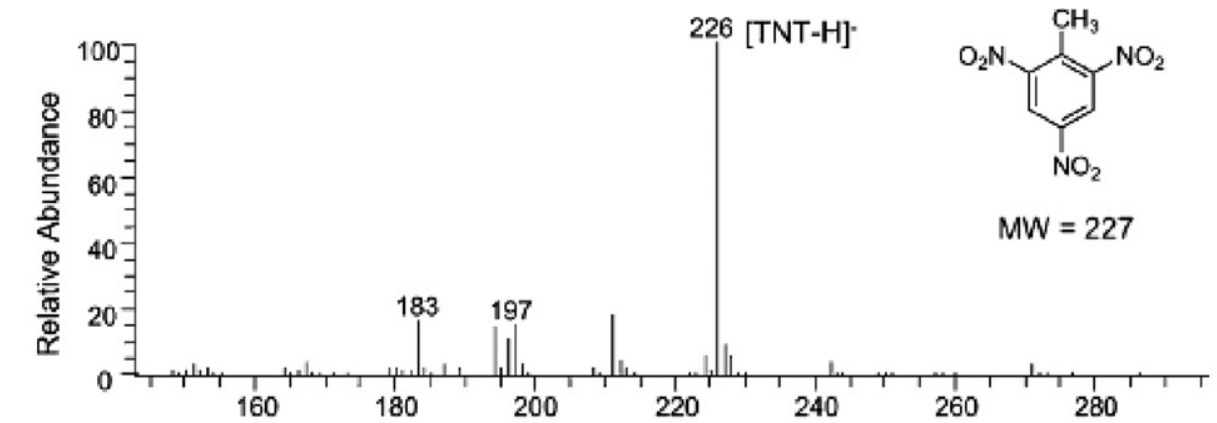

(a)

$m / z$

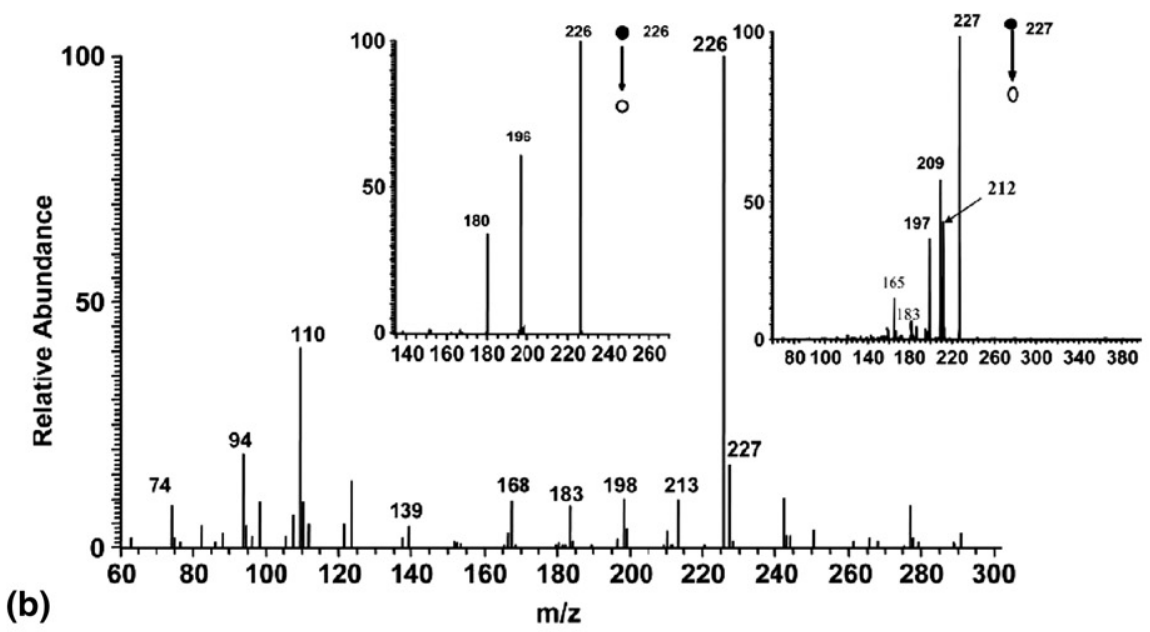

(b)
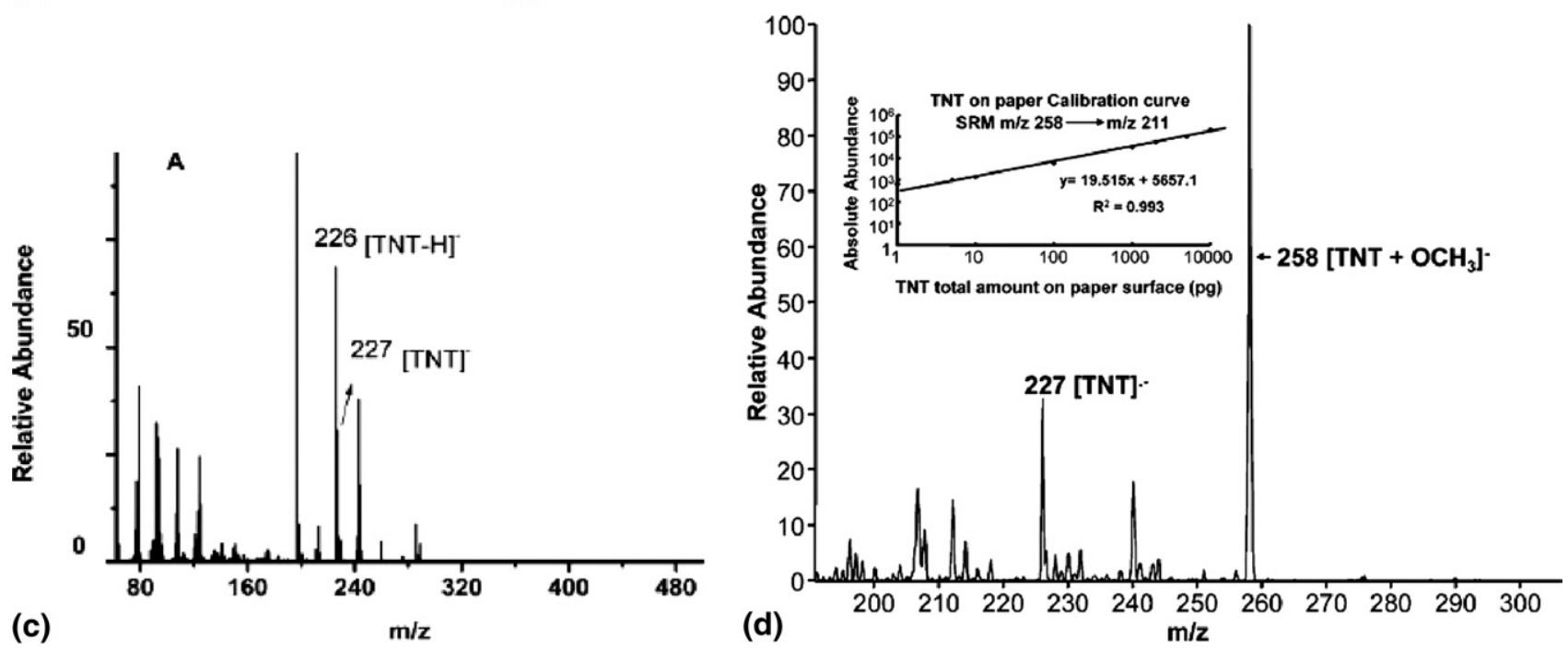

Figure 2. Mass spectra recorded using different ionization techniques, showing the varied ratio of the radical anion of TNT $(\mathrm{m} / \mathrm{z} 227)$ to the deprotonated TNT anion $(\mathrm{m} / \mathrm{z} 226)$. (a) Deprotonated molecules of TNT detected using LTP; reprinted from [92], with permission. Copyright 2009, Royal Society of Chemistry. (b) A typical mass spectrum recorded using DAPCI-MS; reprinted from [46], with permission. Copyright 2007, Wiley. (c) A typical mass spectrum recorded using DBDI, showing predominated fragments $(m / z$ 197, 226) of TNT; reprinted from [47], with permission. Copyright 2007, Wiley. (d) A typical mass spectrum recorded using DESI-MS; reprinted from [86], with permission. Copyright 2005, American Chemical Society. (e) A typical mass spectrum recorded using EESI-MS. No fragment of TNT was observed using EESI; reprinted from [72], with permission. Copyright 2009, Elsevier BV. (f) A typical mass spectrum recorded using SESI-MS. No radical anion of TNT $(\mathrm{m} / \mathrm{z} 227)$ was observed using SESI; reprinted from [137], with permission. Copyright 2009, Elsevier BV. (g) 2,4,6-trinitrotoluene single photon ionization mass spectrum. Lower panel (B) shows an expanded view of the molecular ion region. Reprinted from [97], with permission. Copyright 2006, American Chemical Society. 


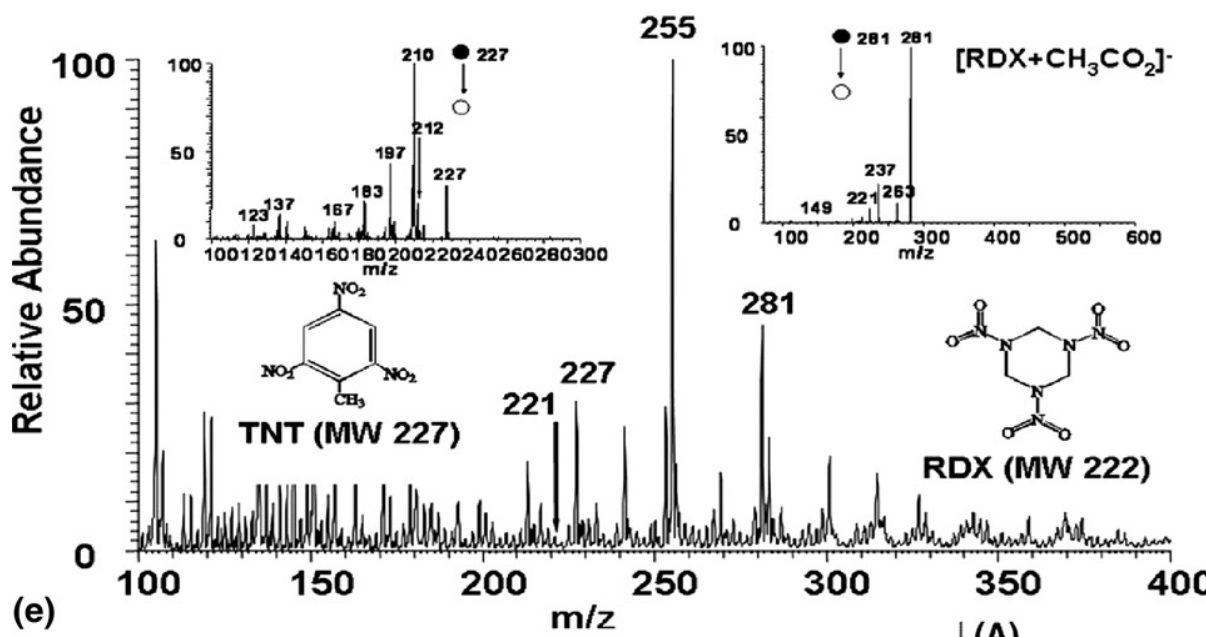

(e)
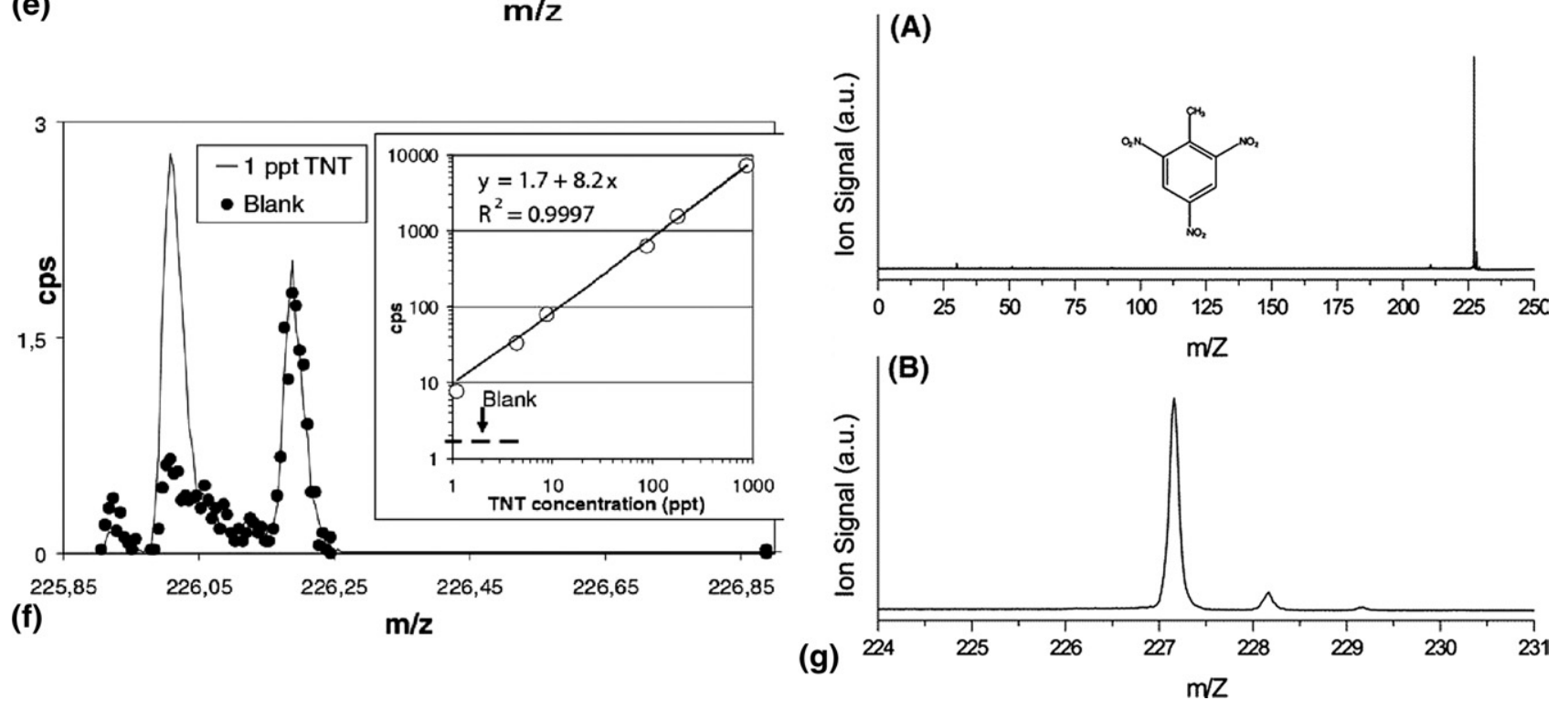

Figure 2. Continued.

matrices on the observed signal via DART analysis [24]. These authors showed how the verapamil analyte signal can be reduced (compared with that in neat solvent) to $50 \%$ in bile, and to $3 \%$ in brain tissue homogenate. An extreme case reported was that of testosterone in rat plasma where the signal was reduced to $0.4 \%$ of the neat solvent signal, however, the authors proposed to use protein precipitation which improved the signal reduction to $9.6 \%$ of the neat solvent signal. Jecklin et al. also showed how the limits of determination vary when analyzing pesticides in different fruit juice matrices via flowing atmospheric-pressure afterglow (FAPA) coupled to tandem mass spectrometry [104] (see Figure 3). It is worth noting that background intensities were not the major contributors to the observed changes.

The above examples serve to show that matrix effects must be taken into account in ambient ionization techniques. We propose that the field of ambient ionization is reaching a certain point of maturity where matrix effects studies need to be conducted to enhance the applicability of the various methods and can even help to elucidate details of the underlying mechanisms.

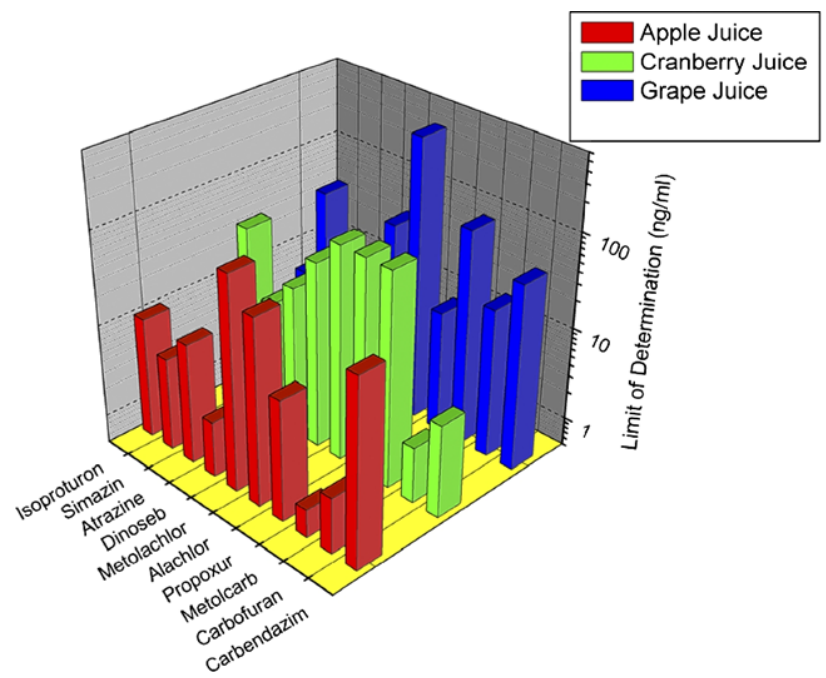

Figure 3. Limits of determination in $\mathrm{ppb}(\mathrm{ng} / \mathrm{mL})$ for several pesticides in different fruit juice matrices analyzed via flowing atmospheric pressure afterglow (FAPA) tandem mass spectrometry. The effect of the matrix on the LODs is evident. The data were taken from [104]. 
Finally, it should be recognized that ambient ionization techniques yield a given type of information which may not be always applicable to current standards in, for example, environmental or food policy, which are customized for benchmark techniques such as chromatographic methods. For instance, the maximum residue levels of pesticides allowed in foods are given in concentration (wt/wt) but the standard procedures consist of homogenizing the samples and performing extractions before analysis. On the other hand, if one were to analyze a fruit directly via ambient ionization techniques, one would have to choose between analyzing the skin, the flesh, and other parts such as the seeds. Jecklin and coworkers used a FAPA source for the rapid screening of pesticides in foodstuff [104]. Not all their samples exhibited the above mentioned issue, for example, fruit juices are fairly homogeneous. However, it is difficult to compare the detection limits obtained from fruit skin/peel to the maximum residue levels allowed. It may not be as straightforward as taking into account the whole weight of the fruit because it has been shown that the concentration of different contaminants can vary between a fruit's flesh and skin [105]. Concerning rapid screening, if a pesticide is below the limit of detection on the skin of a given fruit it could still be possible that a concentration higher than the permitted one exists in the flesh of the fruit. Garcia-Reyes et al. used DESI to perform direct analysis of agrochemicals in fruit peels but also analyzed the extracts from fruits/ vegetables [35]. The latter approach permitted a fairer comparison of the results obtained by DESI and LC-ESIMS. Thus, benchmarking ambient ionization techniques against established standard methods is to a certain degree a problem of representative sampling. It is apparent that either the analyte distribution between sample compartments needs to be considered more carefully or some degree of sample preparation is required (homogenization and/or extraction). This is an important point to contemplate in this case.

\section{In Vivo Analysis}

Another very promising field of application for ambient ionization techniques is in vivo analysis. One of the first examples was a DESI study, which generated mass spectral fingerprints from flowers, plants, and human skin surfaces [2]. Charged droplets from the primary ESI source impact the surface of a living object, and metabolites and airborne compounds accumulated on the surface become detectable. DESI works with many solvents, including water. However, the ionization efficiency for primary ion production in ESI using pure water is low due to the high surface tension of water. Organic solvents such as methanol are usually added into the electrospray solution to achieve the best performance of DESI. Obviously, solutions containing a high percentage of organic solvents are not perfectly compatible for in vivo characterization of biological surfaces, especially for diagnosis of patients with aller- gies. Other techniques such as DAPCI utilize water to efficiently generate the reagent ions $[45,46,59,106]$ and, thus, have been proposed for in vivo characterization of biological surfaces. However, people might be afraid and thus behave abnormally once they see that a "bright fire" (i.e., a high voltage plasma) contacting their skin. The spectra might in this case show unexpected biological responses.

In neutral desorption EESI, living objects are interrogated by a gentle gas stream, much further away from the ESI plume, resulting in neither chemical contamination nor charged particle bombardment of the sample $[34,64,65,70,72,107,108]$. Using a nitrogen or air beam, biological surfaces can be sampled noninvasively and the desorbed products can be transferred along a long tube for remote EESI ionization/detection [71-74, 79]. Therefore, EESI is intrinsically convenient for in vivo analysis, particularly for cases where the samples do not tolerate chemical contamination or interaction with charged particles. Samples with different surfaces, geometries, and sizes can be directly analyzed without tedious source optimization when a sealable ND device [72] is used for sampling. Thus, EESI allows optimal safety and high throughput for in vivo analysis.

\section{Mechanistic Studies}

Most of the publications in the field of ambient ionization MS deal with novel applications. This is important because the wide applicability spectrum of ambient ionization methods is one of the characteristics that have drawn so much attention to the field. On the other hand, not nearly as much attention has been paid to studying the underlying mechanisms characteristic of each technique. This may be one reason why some techniques have different acronyms rather than being recognized as very closely related or even virtually identical. Revealing such fundamental processes are important not only for academic (and terminology) purposes but also to enhance the analytical performance. In this section, we will revisit several ambient ionization methods and review the proposed mechanisms, some of which have only been put forth very recently. The different techniques and their acronyms are compiled in Table 1, according to the dominant desorption/volatilization and ionization processes.

\section{Spray Based Techniques}

The ionization mechanism in DESI has been proposed to be identical to the one characteristic of ESI as evidenced through experimental comparison of corresponding ion internal energies [109]. In brief, the charged droplets evaporate and are subjected to Coulomb explosion processes where ions are generated via ion evaporation or charge residue mechanisms.

Desorption processes in DESI, on the other hand, are very distinctive. A droplet pickup mechanism has been suggested and several studies have shown supporting 
Table 1. Classification of ambient ionization methods according to the dominant desorption/volatilization and ionization mechanisms. Boxes shaded in gray indicate clusters of acronyms that could be replaced by a single acronym

\begin{tabular}{|c|c|c|c|c|c|}
\hline \multirow[b]{2}{*}{$\begin{array}{l}\text { Dominant desorption/ } \\
\text { volatilization method }\end{array}$} & \multicolumn{5}{|c|}{ Dominant ionization/post-ionization method } \\
\hline & Direct & ESI Spray & Chemical post-ionization & $\begin{array}{l}\text { Plasma, Penning, } \\
\text { electrons }\end{array}$ & $\begin{array}{l}\text { Laser or lamp } \\
\text { post-ionization }\end{array}$ \\
\hline (Gas-phase introduction) & & $\begin{array}{l}\text { SESI } \\
\text { EESI }\end{array}$ & & FAPA & \\
\hline (Aerosol introduction) & & $\begin{array}{l}\text { EESI } \\
\text { SESI }\end{array}$ & & & \\
\hline Liquid spray/nebulization & & EESI & & & \\
\hline $\begin{array}{l}\text { Momentum transfer (liquid } \\
\text { or gas jet) }\end{array}$ & & ND-EESI, JEDI & & & DAPPI \\
\hline ESI (including sonic spray) & $\begin{array}{l}\text { DESI, EASI } \\
\text { DeSSI }\end{array}$ & & & & \\
\hline Laser desorption & & $\begin{array}{l}\text { LAESI, ELDI, } \\
\text { (IR-)LADESI }\end{array}$ & $\mathrm{LD} / \mathrm{APCl}$ & LA-FAPA & \\
\hline Energetic particles & DART & & & PADI, FAPA (?) & \\
\hline Plasma & LTP & & $\begin{array}{l}\text { DART, DAPCI, DBDI, LTP, } \\
\text { PADI, DAPI, APGDDI }\end{array}$ & PADI, DART (?) & \\
\hline Thermal desorption & & APTDI & $\begin{array}{l}\text { DART, ASAP, TD-APCI, } \\
\text { LDTD, DAPCI }\end{array}$ & DART, FAPA, APGD & DAPPI \\
\hline Acoustic desorption & & UA-EESI, RADIO & LIAD & & \\
\hline
\end{tabular}

results [110-112]. Phase Doppler anemometry (PDA) was performed on surface-impinging (primary) droplets and progeny (secondary) droplets under typical DESI conditions [110]. The primary droplets exhibit average diameters between $2-4 \mu \mathrm{m}$ and typical velocities of $120 \mathrm{~m} / \mathrm{s}$. This excludes the possibility of direct sputtering through momentum transfer or ionization via shockwave formation. The secondary droplet diameters ranged from $0.5 \mu \mathrm{m}$ (the limit of the PDA instrument) to $10 \mu \mathrm{m}$, with the larger/slower droplets found at greater heights from the surface and the smaller/ faster droplets found closer to the surface. Furthermore, when performing a typical DESI experiment the surface under question is wetted and this is clearly evidenced by visual inspection. Bereman and Muddiman reported a delay in the ion current at the onset of a DESI experiment [113]. This delay is attributed to the time required for dissolving the analyte from the surface into the liquid layer. Costa and Cooks used computational fluid dynamics to model droplet formation and transport processes in DESI [111, 112] (Figure 4). They found that by simulating droplet-thin film collisions, a very good agreement of size, velocity, and angular distribu- tions could be reached with the results obtained experimentally via PDA. This agreement was reached even when electrostatic forces were not taken into account. Their contribution can thus be considered to be minimal and these authors conclude that stochastic momentumtransfer events between primary droplets and the liquid layer are the dominant process in the production of analyte-containing droplets. The shallow optimum "take off" angle for detection is attributed to the smaller droplets being closer to the surface which can be carried by the nebulizing gas jet, as well as to desolvation effects.

It becomes evident that the hydrophilic (or hydrophobic) properties of the substrate used for DESI is an important factor when the requirement for a solvent layer formation on the surface is taken into account [114]. In addition, the electrical conductivity of the substrate also plays a significant role because if a higher amount of charge can be maintained by the substrate it will result in secondary droplets with more charges.

While studying the effects of operating parameters in DESI it was noted that the ion signal intensity does not drop to zero in the absence of an electrospray voltage [41].
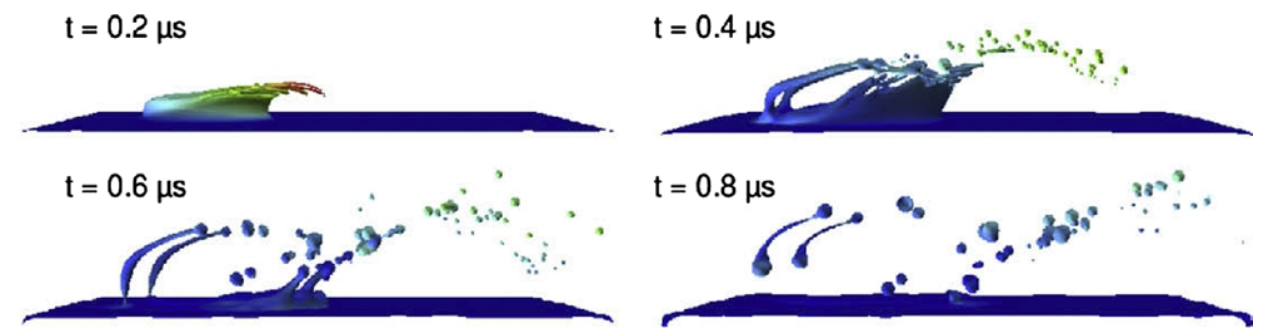

Figure 4. Modeling of progeny droplet formation and transport in DESI at different time steps. Relative velocity is indicated by color (blue $=$ fluid at rest, $\mathrm{red}=$ maximum velocity). With permission from [112], Copyright American Institute of Physics. 
This effect is attributed to production of charged primary droplets through a sonic spray mechanism. This mode of operation was first dubbed desorption sonic spray ionization (DeSSI) [115] and later renamed easy ambient sonicspray ionization (EASI) [116]. Although no fundamental studies specific for the sonic spray mode are available, the use of charged primary droplets should lead to a very similar (if not identical) desorption mechanism to DESI involving droplet/surface-liquid film momentum transfer.

\section{Plasma Based Techniques}

Plasmas are partially ionized gases that can have varying characteristics according to their operating conditions. Some of the major differences between plasma based techniques reside in how the plasma is generated and what kind of reagent species are used for desorption/ionization.

In early 2005, DAPCI was first implemented by replacing a DESI source with a corona source [83]. Thus, reagent ions generated in the corona source region are aimed at the sample, and all reaction products present in typical APCI experiments are observable [91]. APCI ionization mechanisms are well documented and thus outside the scope of this Critical Insight. In atmosphericpressure solids analysis probe (ASAP) [117] desorption is achieved by impinging the sample with a stream of hot nitrogen gas $\left(350-500{ }^{\circ} \mathrm{C}\right)$ inside the chamber of a commercial APCI source. Thus, desorption is achieved by thermal mechanisms and once again ionization patterns typical of APCI are observed.

When DART was reported in early 2005 [3], it was not really clear what type of discharge was utilized, but according to the typical conditions (voltages up to $5 \mathrm{kV}$ and low currents) a corona discharge seemed to be operating. Shelley and coworkers have recently determined that according to the characteristic current/ voltage curves, the plasma in DART is a corona-to-glow transitional discharge [49]. One aspect that makes DART unique compared with other plasma based techniques is that the ionic species generated in the plasma source are filtered to prevent ion-ion recombination losses. The reactive species in the gas stream coming out of the source are mainly highly excited neutrals, for example vibronically excited nitrogen for $\mathrm{N}_{2}$ plasma gas or $\mathrm{He}\left(2^{3} \mathrm{~S}\right)$ metastables for the more commonplace He plasma gas. The reported positive ion background mass spectra are dominated by protonated water clusters [3, 49], which are proposed to form via Penning ionization according to [3]:

$$
\mathrm{He}^{*}+\mathrm{nH}_{2} \mathrm{O} \rightarrow \mathrm{He}+\left(\mathrm{H}_{2} \mathrm{O}\right)_{\mathrm{n}-1} \mathrm{H}^{+}+\mathrm{OH}^{-}
$$

These water clusters are the reactants for proton transfer ionization via Kebarle's water displacement reaction [118]:

$$
\left(\mathrm{H}_{2} \mathrm{O}\right)_{n} \mathrm{H}^{+}+\mathrm{M} \rightarrow \mathrm{M}\left(\mathrm{H}_{2} \mathrm{O}\right)_{n-1} \mathrm{H}^{+}+\mathrm{H}_{2} \mathrm{O}
$$

In the case of negative ionization it was first proposed that electrons coming from Penning ionization of neutrals or surfaces are thermalized thus favoring electron capture processes [3]. A recent study compared negative ionization DART to negative ionization atmospheric pressure photoionization (APPI) using over 42 different compounds [93]. It was found that ionization products for both techniques are very similar and as such four ionization mechanisms were proposed including electron capture, electron capture dissociation, proton transfer, and anion attachment. This is supported by previously reported negative ion DART background spectra containing $\mathrm{O}_{2}^{-}$species and clusters containing water and oxygen [3].

The desorption in the case of volatile species is through thermal mechanisms. IR thermography measurements of a microscope slide exposed to the afterglow of a corona-glow transitional discharge (such as the one in DART but without any additional grids and electrodes) showed a peak temperature of $55^{\circ} \mathrm{C}$ [49] (Figure 5). Thus, higher gas temperatures (up to $250^{\circ} \mathrm{C}$ ) in DART are achieved only through additional heating of the source. For nonvolatile analytes a reactive desorption mechanism involving protonated water clusters collisions with the sample surface, analogous to chemical sputtering, has been proposed [119]. Nevertheless, there is little experimental evidence giving direct support to this hypothesis.

Transport phenomena in DART have been recently studied via finite element method simulations [119] (Figure 6). The gas flow velocity at the exit of the source was calculated to be in the order of $1 \mathrm{~m} / \mathrm{s}$. A larger amount of gas stream lines flowing upward in the sampling region was attributed to the formation of a lower gas density region resulting from the heated helium gas and dissipated heat from the source thus giving a higher-velocity upward gas flow. This is im-

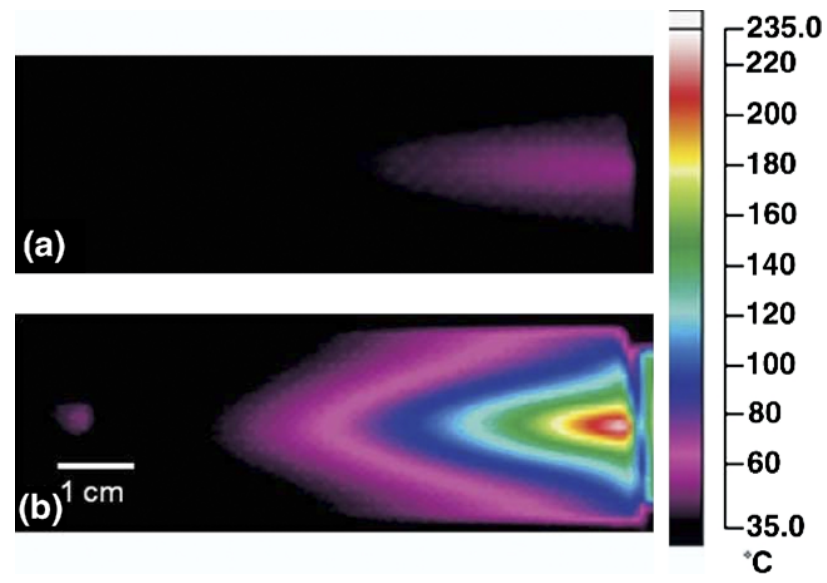

Figure 5. IR thermography images of microscope slide exposed to gas stream emanating from FAPA source (a) and a DART source (b). With permission from [49], Copyright 2009, Elsevier BV. 

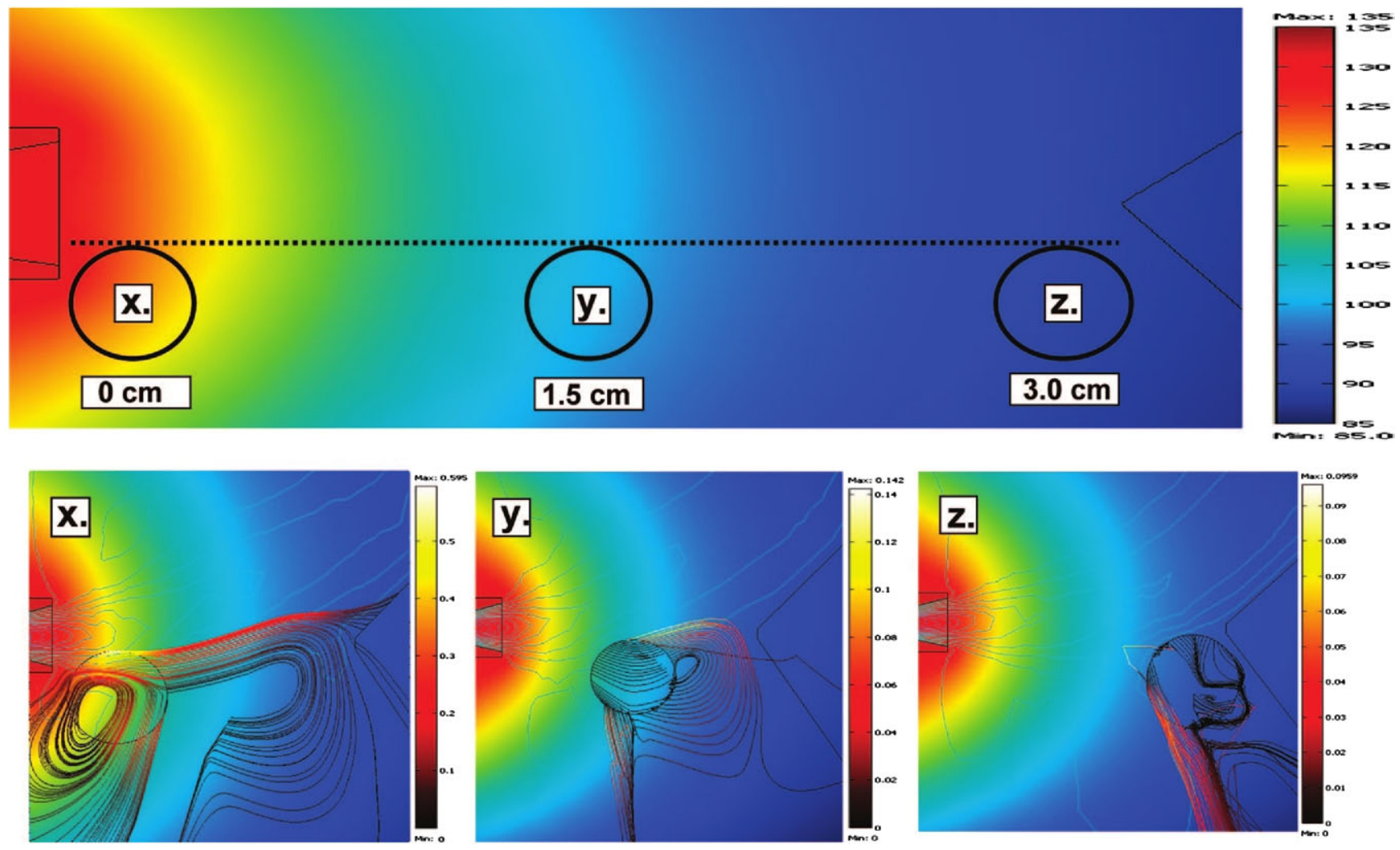

Figure 6. Modeling of DART sampling region including temperature, gas flow and particle tracing. Bottom figures show the behavior in the presence of a tablet-like object at different positions. Upper color scale is for temperature $\left({ }^{\circ} \mathrm{C}\right)$ and bottom color scales pertain to particle velocity $(\mathrm{m} / \mathrm{s})$. With permission from [119], Copyright 2009, American Chemical Society.

portant because simulations showed that the greatest particle flow toward the mass spectrometer sampling cone takes place when a sample tablet is underneath and closest to the exit of the DART source. The orientation of the tablet also plays a crucial role in the calculated particle flows whose trend agrees with experimentally observed ion signal intensities. The temperature maps showed a gradient of $\sim 30{ }^{\circ} \mathrm{C}$ from the exit of the DART source to the tip of the sampling cone. The lower sensitivities observed experimentally at higher DART grid voltages (250-300 V) were attributed to the ions attaining sufficiently high velocity magnitudes, as calculated based on simulations of the electric field, and being directed in trajectories not converging at the sampling orifice.

Another type of plasma sustained at atmospheric pressure used in ambient ionization sources is the glow discharge [32, 120, 121]. Plasma-assisted desorption/ ionization (PADI) is based on a nonthermal rf plasma needle, originally designed for treatment of biomaterials, classified as a glow discharge under the reported operating conditions [122]. The sample in this case is intended to be "in direct contact with the active part of the plasma" [120]. Thus, positive ion production mechanisms have been proposed to include electron impact ionization, Penning ionization, charge-transfer, and proton-transfer reactions. In the case of negative ion formation electron capture and dissociative electron capture and proton transfer have been proposed. Mass spectra featuring $[\mathrm{M}+\mathrm{H}]^{+}$and $[\mathrm{M}-\mathrm{H}]^{-}$support proton transfer mechanisms [120]. Suggested desorption mechanisms include $\mathrm{He}$ metastable energytransfer, ion impact and radical-surface interactions, however, experimental evidence to corroborate any of these processes is lacking.

In FAPA [49], known formerly as the atmospheric pressure glow discharge (APGD) flowing afterglow [32, 121], the recombining flow from a direct current discharge operated in the glow-to-arc transition phase [49, 123], generally with He gas, is used for desorption/ ionization. The background spectra are dominated by water clusters, $\mathrm{NO}^{+}, \mathrm{N}_{2}^{+}$and $\mathrm{O}_{2}^{+}[32,49]$. In addition to direct $\mathrm{He}$ metastable Penning ionization of water clusters, Andrade et al. proposed Penning ionization of $\mathrm{N}_{2}$ molecules [32]:

$$
\mathrm{He}^{*}+\mathrm{N}_{2} \rightarrow \mathrm{He}+\mathrm{N}_{2}^{+}+\mathrm{e}^{-}
$$

Addition of different gases to the enclosed afterglow region showed much greater ionization for added nitrogen (IE $15.6 \mathrm{eV}$ ) or argon (IE $15.7 \mathrm{eV}$ ) compared with neon (IE $21.5 \mathrm{eV}$ ), which indicates a major role of metastable helium $(19.8 \mathrm{eV})$ species in the afterglow [121]. Another reason $\mathrm{N}_{2}^{+}$production is critical pertains 
to water cluster formation, as in APCI, according to [124]. Ionization can then take place via proton transfer (water displacement reaction) and charge exchange or other ion-molecule reactions. Thermally induced desorption mechanisms for volatile species are supported by IR thermography experiments where maximum temperatures around $235^{\circ} \mathrm{C}$ were found on a microscope slide substrate exposed to the afterglow showed under typical operating conditions [49]. Andrade et al. proposed that direct desorption via He metastable collisions with the surface may not be very significant because it is unlikely that such species will be able to reach the surface since they can react so efficiently with so many ambient moieties, however, reactive desorption through background ions may be a more likely process for nonvolatile species [121]. Nevertheless, such mechanisms still need experimental verification.

Dielectric barrier discharges (DBD) have also found their way into ambient ionization mass spectrometry. DBDs consist of microdischarge filaments of nanosecond duration, as opposed to glow discharges which have no radial localization, which results in little gas heating due to their short duration and limited charge transport and energy dissipation. It is worth noting that the same electrode configuration can give rise to a filamentary or glow discharge depending on the operating conditions (gas, voltage, frequency) and the distinction has to be determined experimentally. In dielectric barrier discharge ionization (DBDI) an alternating voltage $\left(20.3 \mathrm{kHz}\right.$, up to $\left.4.5 \mathrm{kV}_{p-p}\right)$ is used to generate a discharge between a needle and a sheet electrode where a dielectric material (glass slide) in between is used to deposit the sample to be desorbed and ionized [125]. Positive ion and negative ion DBDI mass spectra support proton transfer ionization mechanisms, but a comprehensive study to examine several other suggested ionization as well as desorption mechanisms is still needed $[47,125]$. In the low-temperature plasma (LTP) probe, a grounded wire electrode is centered axially inside a glass tube whose outside wall is surrounded with the powered electrode [48]. The plasma gas flow is used to transport the plasma generated species for desorption/ionization purposes. The differences in the mass spectra of the same analytes obtained with different plasma gasses give some clues about the underlying ionization pathways. For example, analyte fragmentation was observed with $\mathrm{N}_{2}$ or air while no fragmentation was observed with He or Ar which suggests direct Penning ionization is not very significant and chargetransfer could account for fragmentation. An interesting feature is that control over the fragmentation patterns was observed by varying the interelectrode distance, which is attributed to increases in the accelerating field for the plasma ions involved in the desorption process. A more comprehensive study is also needed for showing more supporting evidence for ionization and desorption mechanisms. In addition, the nature of the discharge, filamentary or diffuse, is not completely clear.
In desorption atmospheric pressure photoionization (DAPPI), the photons produced in a discharge lamp are used for ionization of analytes directly or indirectly through reactive species of a heated solvent impinged on the surface [29]. Atmospheric pressure photoionization mechanisms are well documented and depend heavily on the ionization energies, proton and electron affinities of analytes and solvents used. A recent study on DAPPI has confirmed several ionization pathways through the use of different solvents [100]. For example, in positive ion mode anisole and toluene solvents yield proton transfer and charge-transfer products while negative mode spectra also support electron capture mechanisms. The effect of different substrates on the sensitivity showed that substrates with lower thermal conductivity display higher sensitivities [100]. A thermal desorption mechanism is further supported by IR thermography images showing higher surface temperatures for the substrates giving higher sensitivities while the type of solvent did not have an observable difference on the heating rate and final temperature of the substrate. A "momentum transfer" mechanism may also come into play since the reported gas velocities (30 $\mathrm{m} / \mathrm{s}$ ) are on the same order as those used in neutral desorption (see below).

\section{Coupled Techniques}

Several methods have taken advantage of the ambient ionization properties of spray or plasma based techniques by desorbing or introducing the sample through a tandem technique.

For example, a series of methods using a laser beam for desorption of solids and liquids have been developed. ELDI uses an electrospray to ionize material ejected from a laser ablation event [126]. One of the motivations is to take advantage of the greater amount of neutrals, compared with ions, produced during laser desorption, but it is not clear how much signal comes from neutrals versus particles ejected. Laser ablation electrospray ionization (LAESI) proposes a new acronym because of the use of an electrospray in the cone-jet regime and a mid-IR laser for ablation, as opposed to ELDI [127]. Nemes and Vertes recall on the difference of the UV versus mid-IR light penetration in the samples (due to linear versus nonlinear absorption coefficients) and the phase explosion induced by mid-IR lasers above certain fluences [127]. The difference in the distance used between the sample and the ESI source in ELDI (approx. $3 \mathrm{~mm}$ ) and LAESI $(30 \mathrm{~mm})$ is also used to show LAESI relies more on the particles ejected, which are able to travel over longer distances. At around the same time IR laser-assisted desorption electrospray ionization (IR LADESI) was introduced with the use of a nanoESI source for ionization [128]. Sampson et al. proposed LAESI and IR LADESI "may be better described as IR-MALDESI" (MALDESI = matrix-assisted laser desorption electrospray ionization) because of the use of water as a matrix [25]. More recently, ESI was 
coupled to laser-induced acoustic desorption (LIAD) where a laser beam is directed at the back of a substrate surface containing the sample and desorption occurs due to the action of the propagating acoustic wave [26].

Laser ablation as well as ESI mechanisms have been widely studied and, to a lesser extent, laser acoustic desorption, and can be called upon to describe these methods. However, the transport mechanisms in between are not so clear. For example, the ablated particles can be engulfed and dissolved by the ESI droplets followed by a conventional ESI mechanism or a DESI mechanism could also be possible for the larger particles. In the case of neutrals, ionization can proceed through gaseous ion-molecule reactions or via incorporation of analytes into droplets.

For a long time, laser desorption has been coupled to plasma based ionization techniques for elemental analysis but only recently with the aim of getting molecular information. Coon et al. developed laser desorption APCI by using a $\mathrm{CO}_{2}$ laser to desorb sample from a liquid matrix [129]. Signal enhancements of more than three orders of magnitude with respect to AP IRMALDI for some protonated molecular ions were reported [130]. Jorabchi and coworkers found, however, that by depositing the sample in an electrically isolated liquid droplet (on insulating support or acoustically levitated) it was possible to charge the droplet with a corona discharge and follow with laser desorption to generate enhanced signal which they termed chargeassisted laser desorption/ionization (CALDI) [131]. The ionization mechanisms are proposed to be MALDI related phenomena and the excess charge serves to prevent ion recombination [132].

In the newly coupled laser ablation/FAPA, some of the mechanistic questions unanswered are of similar nature [133]. How much of the sample is liberated from the laser generated particles via thermal processes and how much is desorbed through other means (e.g., chemical sputtering)?

Several spray/electrospray techniques have also been developed. In FD-ESI, aerosols formed remotely via ultrasonic nebulization and are carried with $\mathrm{N}_{2}$ gas to a glass chamber containing the ESI [134]. The mass spectra obtained were virtually the same as those from conventional ESI except the salt tolerance was greatly enhanced. It was proposed that the aerosols fuse with the electrosprayed droplets followed by normal electrospray ionization mechanisms. On the other hand, it was observed that at high salt concentrations adducts with salt were only present in aqueous ESI solutions, thus it was proposed that precipitation of salts is responsible for their absence in organic ESI solutions [134]. In EESI, a sample is directly nebulized onto the plume of an ESI source thus allowing untreated samples to be analyzed [66]. The proof of principle was performed with a concentric nebulizer, but recently the use of a piezoelectric transducer was proposed [64]. Liquid/liquid extraction between colliding droplets is proposed to allow analytes to be transported into the solvent electrospray.
Radio frequency acoustic desorption and ionization (RADIO) uses a similar approach while using a quartz crystal microbalance (QMC) electrode for nebulization purposes [135]. The QMC in RADIO is driven at 10 $\mathrm{MHz}$, while the piezo transducer in the previously mentioned techniques is closer to $1.5 \mathrm{MHz}$, both in the overlapping radio and ultrasonic frequency ranges. It is not yet clear, however, what gains are obtained by using a higher or lower frequency.

In neutral desorption EESI, a stream of gas is impinged on the sample surface and the resulting liberated (evaporated or aerosolized) analyte is directed toward the ESI source [74]. The impinging gas velocity was reported to be in the order of $10 \mathrm{~m} / \mathrm{s}$. In contrast, DART has been reported to have gas velocities of $1 \mathrm{~m} / \mathrm{s}$ at the source exit [119]. Although the high gas velocities are assumed to help the desorption/aerosolization process, a systematic study on the effect of gas velocity on sensitivity has not been reported so far. Analysis of liquid samples via ND-EESI has also been reported [75]. The configuration is reminiscent of a cross-flow nebulizer and sample liberation is proposed to be due to assisted evaporation and nebulization [75]. The use of the interaction of neutrals with ESI for ionization purposes, however, had been previously reported in secondary electrospray ionization (SESI) [6]. The ionization mechanisms have been proposed to go through two paths, including incorporation of the neutrals into the electrosprayed droplets and/or gas-phase ion-molecule reactions with electrospray-produced ions. The contribution of one mechanism as opposed to the other remains unclear and it probably changes according to the analyte and ESI solvent characteristics.

One theme is clear throughout the reviewed techniques: we are still far from fully understanding all the mechanisms. Hard proof is still lacking, even when some mechanisms have been proposed. Thus, much work is needed to fill the current information gaps preventing the proof and/or rejection of hypothesized processes, which will ultimately lead to improved techniques.

\section{Terminology: "Biodiversity in the Acronym Zoo"}

It is widely recognized that there are too many acronyms being generated for closely related ambient MS methods (for a compilation of acronyms, see Table 1). At a recent symposium on Ambient Ionization Mass Spectrometry at Pittcon '09 in Chicago, several speakers declared that there should be "a moratorium on the creation of further acronyms." Cooks and coworkers, in their short reviews on ambient desorption/ionization MS in 2008 and 2009 [1, 136], listed 17 different acronyms; Van Berkel's review on atmospheric pressure surface sampling/ionization techniques [8] listed 25 different acronyms! As already stated in the literature [1], some "catchy" acronyms (for example, DART or 
ASAP) were chosen to be recognized as marketing tools for commercial implementations rather than being descriptive of certain processes occurring. On the other hand, there have also been arguments in the literature about the precise nomenclature for an accurate distinction between closely related methods. For example, some authors are adamant about a differentiation between EESI and SESI, a method and acronym originally introduced by Hill and coworkers [6]: for example, Martinez-Lozano and co-authors [137] argue that in cases where breath is analyzed, one should use the term SESI, whereas in our work on breath analysis, the acronym EESI was always used $[5,138]$ to indicate that breath is in fact an aerosol [139]. Yet other workers refer to this process as FD-ESI [134, 140], and there are close similarities to a method called "remote reagent chemical ionization," which has appeared in the patent literature [141]. We suggest that these differences are not important enough to justify the use of more than one acronym. SESI, which is probably the most general description, could be used in all cases. A similar confusion about the use of acronyms has arisen for the laser-assisted methods (ELDI, MALDESI, LAESI, etc.). Are they really that different or are they rather characterized by similarities? The inventors of the different variants of methods based on laser desorption followed by ESI-postionization do point out distinguishing features, for example the use of an IR laser with a wavelength at $2.94 \mu \mathrm{m}$, which is absorbed by the aqueous environment in biological samples in LAESI, versus other wavelengths in other embodiments. Again, we argue that the differences between these methods are too small to justify $\geq 4$ acronyms.

Table 1 summarizes the different techniques and according acronyms for ambient ionization, by classifying them according to the method used for volatilization/desorption of the analyte (e.g., thermal desorption, laser desorption, or a plasma source) and the method used for ionization (e.g., using an ionizing ESI spray). Note that in a few cases, desorption/ionization happens in a single step (e.g., in DESI), in which case the corresponding technique is listed in the column with the heading "direct." Several methods appear in more than one box, e.g., DAPPI. As noted before desorption in DAPPI could take place by a thermal mechanism, by momentum transfer, or a combination thereof. One will also note that some boxes in the table are populated with several acronyms; these are techniques that we propose could be named with a single acronym.

\section{Acknowledgments}

The authors owe thanks to Mr. Bin Hu for his kind help in preparing some of the figures. The authors acknowledge support in part for this work by the Innovation Method Fund of China (2008IM040400) and by a grant from the Sino-Swiss Science and Technology Cooperation (no. IZLCZ 2123987).

\section{References}

1. Venter, A.; Nefliu, M.; Cooks, R. G. Ambient Desorption Ionization Mass Spectrometry. TrAC 2008, 27, 284-290.

2. Takats, Z.; Wiseman, J. M.; Gologan, B.; Cooks, R. G. Mass Spectrometry Sampling Under Ambient Conditions with Desorption Electrospray Ionization. Science 2004, 306, 471-473.

3. Cody, R. B.; Laramee, J. A.; Durst, H. D. Versatile New Ion Source for the Analysis of Materials in Open Air Under Ambient Conditions. Anal. Chem. 2005, 77, 2297-2302.

4. Chen, H. W.; Talaty, N. N.; Takats, Z.; Cooks, R. G. Desorption Electrospray Ionization Mass Spectrometry for High-Throughput Analysis of Pharmaceutical Samples in the Ambient Environment. Anal. Chem. 2005, 77, 6915-6927.

5. Chen, H. W.; Wortmann, A.; Zhang, W. H.; Zenobi, R. Rapid In Vivo Fingerprinting of Nonvolatile Compounds in Breath by Extractive Electrospray Ionization Quadrupole Time-of-Flight Mass Spectrometry. Angew. Chem. Int. Ed. 2007, 46, 580-583.

6. Wu, C.; Siems, W. F.; Hill, H. H. Secondary Electrospray Ionization Ion Mobility Spectrometry/Mass Spectrometry of Illicit Drugs. Anal. Chem. 2000, 72, 396-403.

7. Steiner, W. E.; Clowers, B. H.; Haigh, P. E.; Hill, H. H. Secondary Ionization of Chemical Warfare Agent Simulants: Atmospheric Pressure Ion Mobility Time-of-Flight Mass Spectrometry. Anal. Chem. 2003 75, 6068-6076.

8. Van Berkel, G. J.; Pasilis, S. P.; Ovchinnikova, O. Established and Emerging Atmospheric Pressure Surface Sampling/Ionization Techniques for Mass Spectrometry. J. Mass Spectrom. 2008, 43, 1161-1180.

9. Kornienko, O.; Reilly, P. T. A.; Whitten, W. B.; Ramsey, J. M. Electron Impact Ionization in a Micro-Ion Trap Mass Spectrometer. Rev. Sci. Instrum. 1999, 70, 3907-3909.

10. Pau, S.; Pai, C. S.; Low, Y. L.; Moxom, J.; Reilly, P. T.; Whitten, W. B.; Ramsey, J. M. Microfabricated Quadrupole Ion Trap for Mass Spectrometer Applications. Phys. Rev. Lett. 2006, 96, 120801.

11. Keil, A.; Talaty, N.; Janfelt, C.; Noll, R. J.; Gao, L.; Ouyang, Z.; Cooks, R. G. Ambient Mass Spectrometry with a Handheld Mass Spectrometer at High Pressure. Anal. Chem. 2007, 79, 7734-7739.

12. Yang, M.; Kim, T.Y.; Hwang, H.C.; Yi, S.K.; Kim, D.H. Development of a Palm Portable Mass Spectrometer. J. Am. Soc. Mass Spectrom. 2008, 19, 1442-1448.

13. Griffin, T. P.; Diaz, J. A.; Arkin, C. R.; Soto, C.; Curley, C. H.; Gomez, O. Three-Dimensional Concentration Mapping of Gases Using a Portable Mass Spectrometer System. J. Am. Soc. Mass Spectrom. 2008, 19, 1411-1418.

14. Ouyang, Z.; Noll, R. J.; Cooks, R. G. Handheld Miniature Ion Trap Mass Spectrometers. Anal. Chem. 2009, 81, 2421-2425.

15. Taylor, S.; Bierbaum, V. M. Focus on Harsh Environment Mass Spectrometry. J. Am. Soc. Mass Spectrom. 2008, 19, 1375-1376.

16. Herrero, F. A.; Jones, H. H.; Lee, J. G. The Gated Electrostatic Mass Spectrometer (GEMS): Definition and Preliminary Results. J. Am. Soc. Mass Spectrom. 2008, 19, 1384-1394.

17. Schlüter, M.; Gentz, T. Application of Membrane Inlet Mass Spectrometry for Online and In Situ Analysis of Methane in Aquatic Environments. J. Am. Soc. Mass Spectrom. 2008, 19, 1395-1402.

18. Contreras, J. A.; Murray, J. A.; Tolley, S. E.; Oliphant, J. L.; Tolley, H. D.; Lammert, S. A.; Lee, E. D.; Later, D. W.; Lee, M. L. HandPortable Gas Chromatograph-Toroidal Ion Trap Mass Spectrometer (GC-TMS) for Detection of Hazardous Compounds. J. Am. Soc. Mass Spectrom. 2008, 19, 1425-1434.

19. Hoffman, J. H.; Chaney, R. C.; Hammack, H. Phoenix Mars MissionThe Thermal Evolved Gas Analyzer. J. Am. Soc. Mass Spectrom. 2008, 19, 1377-1383

20. Wells, J. M.; Roth, M. J.; Keil, A. D.; Grossenbacher, J. W.; Justes, D. R.; Patterson, G. E.; Barket, D. J., Jr. Implementation of DART and DESI Ionization on a Fieldable Mass Spectrometer. J. Am. Soc. Mass Spectrom. 2008, 19, 1419-1424.

21. Austin, D. E.; Peng, Y.; Hansen, B. J.; Miller, I. W.; Rockwood, A. L.; Hawkins, A. R.; Tolley, S. E. Novel Ion Traps Using Planar Resistive Electrodes: Implications for Miniaturized Mass Analyzers. J. Am. Soc. Mass Spectrom. 2008, 19, 1435-1441.

22. Hemond, H. F.; Mueller, A. V.; Hemond, M. Field Testing of Lake Water Chemistry with a Portable and AVU-based Mass Spectrometer. J. Am. Soc. Mass Spectrom. 2008, 19, 1403-1410.

23. Wiseman, J. M.; Ifa, D. R.; Venter, A.; Cooks, R. G. Ambient Molecular Imaging by Desorption Electrospray Ionization Mass Spectrometry. Nature Prot. 2008, 3, 517-524.

24. Yu, S. X.; Crawford, E.; Tice, J.; Musselman, B.; Wu, J. T. Bioanalysis without Sample Cleanup or Chromatography: The Evaluation and Initial Implementation of Direct Analysis in Real Time Ionization Mass Spectrometry for the Quantification of Drugs in Biological Matrixes. Anal. Chem. 2009, 81, 193-202.

25. Sampson, J. S.; Murray, K. K.; Muddiman, D. C. Intact and Top-Down Characterization of Biomolecules and Direct Analysis Using Infrared Matrix-Assisted Laser Desorption Electrospray Ionization Coupled to FT-ICR, Mass Spectrometry. J. Am. Soc. Mass Spectrom. 2009, 20, 667-673.

26. Cheng, S. C.; Cheng, T. L.; Chang, H. C.; Shiea, J. Using Laser-Induced Acoustic Desorption/Electrospray Ionization Mass Spectrometry to Characterize Small Organic and Large Biological Compounds in the 
Solid State and in Solution Under Ambient Conditions. Anal. Chem. 2009, 81, 868-874.

27. Wiseman, J. M.; Puolitaival, S. M.; Takats, Z.; Cooks, R. G.; Caprioli, R. M. Mass Spectrometric Profiling of Intact Biological Tissue by Using Desorption Electrospray Ionization. Angew. Chem. Int. Ed. 2005, 44, 7094-7097.

28. Wiseman, J. M.; Ifa, D. R.; Zhu, Y. X.; Kissinger, C. B.; Manicke, N. E.; Kissinger, P. T.; Cooks, R. G. Desorption Electrospray Ionization Mass Spectrometry: Imaging Drugs and Metabolites in Tissues. Proc. Natl. Acad. Sci. U.S.A. 2008, 105, 18120-18125.

29. Haapala, M.; Pol, J.; Saarela, V.; Arvola, V.; Kotiaho, T.; Ketola, R. A.; Franssila, S.; Kauppila, T. J.; Kostiainen, R. Desorption Atmospheric Pressure Photoionization. Anal. Chem. 2007, 79, 7867-7872.

30. Kauppila, T. J.; Wiseman, J. M.; Ketola, R. A.; Kotiaho, T.; Cooks, R. G.; Kostiainen, R. Desorption Electrospray Ionization Mass Spectrometry for the Analysis of Pharmaceuticals and Metabolites. Rapid Commun. Mass Spectrom. 2006, 20, 387-392.

31. Corso, G.; Paglia, G.; Garofalo, D.; D'Apolito, O.. Neutral Loss Analysis of Amino Acids by Desorption Electrospray Ionization Using an Unmodified Tandem Quadrupole Mass Spectrometer. Rapid Commun. Mass Spectrom. 2007, 21, 3777-3784.

32. Andrade, F. J.; Shelley, J. T.; Wetzel, W. C.; Webb, M. R.; Gamez, G.; Ray, S. J.; Hieftje, G. M. Atmospheric Pressure Chemical Ionization Source. 1. Ionization of Compounds in the Gas Phase. Anal. Chem. 2008, 80, 2646-2653.

33. Laramee, J. A.; Durst, H. D.; Connell, T. R.; Nilles, J. M. Detection of Chemical Warfare Agents on Surfaces Relevant to Homeland Security by Direct Analysis in Real-Time Spectrometry. Am. Lab. 2008, 40, $16-21$

34. Li, J. Q.; Zhou, Y. F.; Ding, J. H.; Yang, S. P.; Cheng, H. W. Rapid Detection of Toluene-2,4-diisocyanate in Various Sports Fields Using Extractive Electrospray Ionization Mass Spectrometry. Chin. J. Anal. Chem. 2008, 36, 1300-1304.

35. Garcia-Reyes, J. F.; Jackson, A. U.; Molina-Diaz, A.; Cooks, R. G. Desorption Electrospray Ionization Mass Spectrometry for Trace Analysis of Agrochemicals in Food. Anal. Chem. 2009, 81, 820-829.

36. Vaclavik, L.; Cajka, T.; Hrbek, V.; Hajslova, J. Ambient Mass Spectrometry Employing Direct Analysis in Real Time (DART) Ion Source for Olive Oil Quality and Authenticity Assessment. Anal. Chim. Acta. 2009, $645,56-63$

37. Yang, S. P.; Ding, J. H.; Zheng, J.; Hu, B.; Li, J. Q.; Chen, H. W.; Zhou, Z. Q.; Qiao, X. L. Detection of Melamine in Milk Products by Surface Desorption Atmospheric Pressure Chemical Ionization Mass Spectrometry. Anal. Chem. 2009, 81, 2426-2436.

38. Huang, G.; Ouyang, Z.; Cooks, R. G. High-Throughput Trace Melamine Analysis in Complex Mixtures. Chem. Commun. 2009, 556-558.

39. Cotte-Rodriguez, I.; Mulligan, C. C.; Cooks, G. Nonproximate Detection of Small and Large Molecules by Desorption Electrospray Ionization and Desorption Atmospheric Pressure Chemical Ionization Mass Spectrometry: Instrumentation and Applications in Forensics, Chemistry, and Biology. Anal. Chem. 2007, 79, 7069-7077.

40. Ifa, D. R.; Gumaelius, L. M.; Eberlin, L. S.; Manicke, N. E.; Cooks, R. G. Forensic Analysis of Inks by Imaging Desorption Electrospray Ionization (DESI) Mass Spectrometry. Analyst 2007, 132, 461-467.

41. Takats, Z.; Wiseman, J. M.; Cooks, R. G. Ambient Mass Spectrometry using Desorption Electrospray Ionization (DESI): Instrumentation, Mechanisms, and Applications in Forensics, Chemistry, and Biology. J. Mass Spectrom. 2005, 40, 1261-1275.

42. D'Agostino, P. A.; Hancock, J. R.; Chenier, C. L.; Lepage, C. R. J. Liquid Chromatography Electrospray Tandem Mass Spectrometric and Desorption Electrospray Ionization Tandem Mass Spectrometric Analysis of Chemical Warfare Agents in Office Media Typically Collected During a Forensic Investigation. J. Chromatogr. A 2006, 1110, 86-94.

43. Bedair, M.; Sumner, L. W. Current and Emerging Mass-Spectrometry Technologies for Metabolomics. Trac-Trends Anal. Chem. 2008, 27, 238-250.

44. Cooks, R. G.; Ouyang, Z.; Takats, Z.; Wiseman, J. M. Ambient Mass Spectrometry. Science 2006, 311, 1566-1570.

45. Chen, H. W.; Lai, J. H.; Zhou, Y. F.; Huan, Y. F.; Li, J. Q.; Zhang, X.; Wang, Z. C.; Luo, M. B. Instrumentation and Characterization of Surface Desorption Atmospheric Pressure Chemical Ionization Mass Spectrometry. Chin. J. Anal. Chem. 2007, 35, 1233-1240.

46. Chen, H. W.; Zheng, J.; Zhang, X.; Luo, M. B.; Wang, Z. C.; Qiao, X. L. Surface Desorption Atmospheric Pressure Chemical Ionization Mass Spectrometry for Direct Ambient Sample Analysis Without Toxic Chemical Contamination. J. Mass Spectrom. 2007, 42, 1045-1056.

47. Na, N.; Zhang, C.; Zhao, M. X.; Zhang, S. C.; Yang, C. D.; Fang, X.; Zhang, X. R. Direct Detection of Explosives on Solid Surfaces by Mass Spectrometry with an Ambient Ion Source Based on Dielectric Barrier Discharge. J. Mass Spectrom. 2007, 42, 1079-1085.

48. Harper, J. D.; Charipar, N. A.; Mulligan, C. C.; Zhang, X. R.; Cooks, R. G.; Ouyang, Z. Low-Temperature Plasma Probe for Ambient Desorption Ionization. Anal. Chem. 2008, 80, 9097-9104.

49. Shelley, J. T.; Wiley, J. S.; Chan, G. C. Y.; Schilling, G. D.; Ray, S. J.; Hieftje, G. M. Characterization of Direct-Current AtmosphericPressure Discharges Useful for Ambient Desorption/Ionization Mass Spectrometry. J. Am. Soc. Mass Spectrom. 2009, 20, 837-844.

50. Cody, R. B. Observation of Molecular Ions and Analysis of Nonpolar Compounds with the Direct Analysis in Real Time Ion Source. Anal. Chem. 2009, 81, 1101-1107.
51. Soparawalla, S.; Salazar, G. A.; Perry, R. H.; Nicholas, M.; Cooks, R. G. Pharmaceutical Cleaning Validation Using Nonproximate Large-Area Desorption Electrospray Ionization Mass Spectrometry. Rapid Commun. Mass Spectrom. 2009, 23, 131-137.

52. Wiseman, J. M.; Ifa, D. R.; Song, Q. Y.; Cooks, R. G. Tissue Imaging at Atmospheric Pressure Using Desorption Electrospray Ionization (DESI) Mass Spectrometry. Angew. Chem. Int. Ed. 2006, 45, 7188-7192

53. Ifa, D. R.; Manicke, N. E.; Dill, A. L.; Cooks, G. Latent Fingerprint Chemical Imaging by Mass Spectrometry. Science 2008, 321, 805.

54. Kertesz, V.; Van Berkel, G. J. Improved Imaging Resolution in Desorption Electrospray Ionization Mass Spectrometry. Rapid Commun. Mass Spectrom. 2008, 22, 2639-2644.

55. Ifa, D. R.; Wiseman, J. M.; Song, Q. Y.; Cooks, R. G. Development of Capabilities for Imaging Mass Spectrometry Under Ambient Conditions with Desorption Electrospray Ionization (DESI). Int. J. Mass Spectrom. 2007, 259, 8-15.

56. Kertesz, V.; Van Berkel, G. J. Improved Desorption Electrospray Ionization Mass Spectrometry Performance Using Edge Sampling and a Rotational Sample Stage. Rapid Commun. Mass Spectrom. 2008, 22 3846-3850.

57. Esquenazi, E.; Dorrestein, P. C.; Gerwick, W. H. Probing Marine Natural Product Defenses with DESI-Imaging Mass Spectrometry. Proc. Natl. Acad. Sci. U.S.A. 2009, 106, 7269-7270.

58. Lane, A. L.; Nyadong, L.; Galhena, A. S.; Shearer, T. L.; Stout, E. P. Parry, R. M.; Kwasnik, M.; Wang, M. D.; Hay, M. E.; Fernandez, F. M.; Kubanek, J. Desorption Electrospray Ionization Mass Spectrometry Reveals Surface-Mediated Antifungal Chemical Defense of a Tropical Seaweed. Proc. Natl. Acad. Sci. U.S.A. 2009, 106, 7314-7319.

59. Yang, S.; Chen, H.-W.; Yang, Y.-L.; Hu, B.; Zhang, X.; Zhou, Y.-F.; Zhang, L.-L.; Gu, H.-W. Imaging Melamine in Egg Samples by Surface Desorption Atmospheric Pressure Chemical Ionization Mass Spectrometry. Chin. J. Anal. Chem. 2009, 37, 315-318.

60. Nemes, P.; Barton, A. A.; Li, Y.; Vertes, A. Ambient Molecular Imaging and Depth Profiling of Live Tissue by Infrared Laser Ablation Electrospray Ionization Mass Spectrometry. Anal. Chem. 2008, 80, 4575-4582.

61. Piggee, C. In Vivo Molecular Imaging by LAESI MS. Anal. Chem. 2008, 80,4783 .

62. Williams, J. P.; Patel, V. J.; Holland, R.; Scrivens, J. H. The Use of Recently Described Ionization Techniques for the Rapid Analysis of Some Common Drugs and Samples of Biological Origin. Rapid Commun. Mass Spectrom. 2006, 20, 1447-1456.

63. Chipuk, J. E.; Brodbelt, J. S. Transmission Mode Desorption Electrospray Ionization. J. Am. Soc. Mass Spectrom. 2008, 19, 1612-1620.

64. Zhu, L.; Gamez, G.; Chen, H. W.; Chingin, K.; Zenobi, R. Rapid Detection of Melamine in Untreated Milk and Wheat Gluten by Ultrasound-Assisted Extractive Electrospray Ionization Mass Spectrometry (EESI-MS). Chem. Commun. 2009, 559-561.

65. Chingin, K.; Gamez, G.; Chen, H. W.; Zhu, L.; Zenobi, R. Rapid Classification of Perfumes by Extractive Electrospray Ionization Mass Spectrometry (EESI-MS). Rapid Commun. Mass Spectrom. 2008, 22, 2009-2014.

66. Chen, H. W.; Venter, A.; Cooks, R. G. Extractive Electrospray Ionization for Direct Analysis of Undiluted Urine, Milk and Other Complex Mixtures Without Sample Preparation. Chem. Commun. 2006, 2042 2044.

67. Miao, Z.; Chen, H. Direct Analysis of Liquid Samples by Desorption Electrospray Ionization-Mass Spectrometry (DESI-MS) J. Am. Soc. Mass Spectrom. 2008, 20, 10-19.

68. Gu, H. W.; Chen, H. W.; Pan, Z. Z.; Jackson, A. U.; Talaty, N.; Xi, B. W.; Kissinger, C.; Duda, C.; Mann, D.; Raftery, D.; Cooks, R. G. Monitoring Diet Effects via Biofluids and Their Implications for Metabolomics Studies. Anal. Chem. 2007, 79, 89-97.

69. Zhou, Z. Q.; Jin, M.; Ding, J. H.; Zhou, Y. M.; Zheng, J.; Chen, H. W. Rapid Detection of Atrazine and its Metabolite in Raw Urine by Extractive Electrospray Ionization Mass Spectrometry. Metabolomics 2007, 3, 101-104

70. Law, W.; Ding, J.; Chen, H.; Wu, Z.; Ren, Y.; Zenobi, R. EESI MS for Direct Analysis of Samples of High Viscosity Angew. Chem. Int. Ed. 2009, doi:10.1002/anie.200902360.

71. Chen, H. W.; Wortmann, A.; Zenobi, R. Neutral Desorption Sampling Coupled to Extractive Electrospray Ionization Mass Spectrometry for Rapid Differentiation of Bilosamples by Metabolomic Fingerprinting. J. Mass Spectrom. 2007, 42, 1123-1135.

72. Chen, H. W.; Hu, B.; Hu, Y.; Huan, Y. F.; Zhou, Z. Q.; Qiao, X. F. Neutral Desorption Using a Sealed Enclosure to Sample Explosives on Human Skin for Rapid Detection by EESI-MS. J. Am. Soc. Mass Spectrom. 2009, 20, 719-722.

73. Chen, H.; Zenobi, R. Neutral Desorption Sampling Extractive Electrospray Ionization Mass Spectrometry for In Vivo Analysis. Nature Prot. 2008, 3, 1467-1475.

74. Chen, H.; Yang, S.; Wortmann, A.; Zenobi, R. Neutral Desorption Sampling of Living Objects for Rapid Analysis by Extractive Electrospray Ionization Mass Spectrometry. Angew. Chem. Int. Ed. 2007, 46, 7591-7594.

75. Chingin, K.; Chen, H.; Gamez, G.; Zhu, L.; Zenobi, R. Detection of Diethyl Phthalate in Perfumes by Extractive Electrospray Ionization Mass Spectrometry. Anal. Chem. 2009, 81, 123-129.

76. Luque de Castro, M. D.; Priego-Capote, F. Analytical Applications of Ultrasound Series; Elsevier: Amsterdam, The Netherlands, 2006; pp $56-66$ 
77. Luque de Castro, M. D.; Priego-Capote, F. Lesser Known UltrasoundAssisted Heterogeneous Sample-Preparation Procedures. TrAC 2007, $26,154-162$.

78. Chen, H. W.; Sun, Y. P.; Wortmann, A.; Gu, H. W.; Zenobi, R. Differentiation of Maturity and Quality of Fruit Using Noninvasive Extractive Electrospray Ionization Quadrupole Time-of-Flight Mass Spectrometry. Anal. Chem. 2007, 79, 1447-1455.

79. Chen, H. W.; Yang, S.; Wortmann, A.; Zenobi, R. Neutral Desorption Sampling of Living Objects for Rapid Analysis by Extractive Electrospray Ionization Mass Spectrometry. Angew. Chem. Int. Ed. 2007, 46, 7591-7594.

80. Vail, T. M.; Jones, P. R.; Sparkman, O. D. Rapid and Unambiguous Identification of Melamine in Contaminated Pet Food Based on Mass Spectrometry with Four Degrees of Confirmation. J. Anal. Toxicol. 2007, 31, 304-312.

81. Shiea, J.; Personal Communication, 2008

82. http://www.food.gov.uk/news/newsarchive/2008/sep/melamine, accessed May 2009

83. Takáts, Z.; Cotte-Rodriguez, I.; Talaty, N.; Chen, H.; Cooks, R. G. Direct, Trace Level Detection of Explosives on Ambient Surfaces by Desorption Electrospray Ionization Mass Spectrometry. Chem. Commun. 2005, 1950-1952.

84. Cotte-Rodriguez, I.; Chen, H.; Cooks, R. G. Rapid Trace Detection of Triacetone Triperoxide (TATP) by Complexation Reactions During Desorption Electrospray Ionization. Chem. Commun. 2006, 953-955.

85. Nyadong, L.; Green, M. D.; De Jesus, V. R.; Newton, P. N.; Fernandez, F. M. Reactive Desorption Electrospray Ionization Linear Ion Trap Mass Spectrometry of Latest-Generation Counterfeit Antimalarials via Noncovalent Complex Formation. Anal. Chem. 2007, 79, 2150-2157.

86. Cotte-Rodriguez, I.; Takats, Z.; Talaty, N.; Chen, H. W.; Cooks, R. G. Desorption Electrospray Ionization of Explosives on Surfaces: Sensitivity and Selectivity Enhancement by Reactive Desorption Electrospray Ionization. Anal. Chem. 2005, 77, 6755-6764.

87. Cotte-Rodriguez, I; Cooks, R. G. Nonproximate Detection of Explosives and Chemical Warfare Agent Simulants by Desorption Electrospray Ionization Mass Spectrometry. Chem. Commun. 2006, 2968-2970.

88. Justes, D. R.; Talaty, N.; Cotte-Rodriguez, I.; Cooks, R. G. Detection of Explosives on Skin Using Ambient Ionization Mass Spectrometry. Chem. Commun. 2007, 2142-2144.

89. Talaty, N.; Mulligan, C. C.; Justes, D. R.; Jackson, A. U.; Noll, R. J.; Cooks, R. G. Fabric Analysis by Ambient Mass Spectrometry for Explosives and Drugs. Analyst. 2008, 133, 1532-1540.

90. Venter, A.; Cooks, R. G. Desorption Electrospray Ionization in a Small Pressure-Tight Enclosure. Anal. Chem. 2007, 79, 6398-6403.

91. Song, Y. S.; Cooks, R. G. Atmospheric Pressure Ion/Molecule Reactions for the Selective Detection of Nitroaromatic Explosives Using Acetonitrile and Air as Reagents. Rapid Commun. Mass Spectrom. 2006, 20, 3130-3138.

92. Zhang, Y.; Ma, X. X.; Zhang, S. C.; Yang, C. D.; Ouyang, Z.; Zhang, $X$. R. Direct Detection of Explosives on Solid Surfaces by Low Temperature Plasma Desorption Mass Spectrometry. Analyst 2009, 134, $176-181$.

93. Song, L. G.; Dykstra, A. B.; Yao, H. F.; Bartmess, J. E. Ionization Mechanism of Negative Ion-Direct Analysis in Real Time: A Comparative Study with Negative Ion-Atmospheric Pressure Photoionization. I. Am. Soc. Mass Spectrom. 2009, 20, 42-50.

94. Peng, I. X.; Loo, R. R. O.; Shiea, J.; Loo, J. A. Reactive-ElectrosprayAssisted Laser Desorption/Ionization for Characterization of Peptides and Proteins. Anal. Chem. 2008, 80, 6995-7003.

95. Tam, M.; Hill, H. H. Secondary Electrospray Ionization-Ion Mobility Spectrometry for Explosive Vapor Detection. Anal. Chem. 2004, 76, 2741-2747.

96. Martin, A. N.; Farquar, G. R.; Gard, E. E.; Frank, M.; Fergenson, D. P. Identification of High Explosives Using Single-Particle Aerosol Mass Spectrometry. Anal. Chem. 2007, 79, 1918-1925.

97. Mullen, C.; Irwin, A.; Pond, B. V.; Huestis, D. L.; Coggiola, M. J.; Oser, $\mathrm{H}$. Detection of Explosives and Explosives-Related Compounds by Single Photon Laser Ionization Time-of-Flight Mass Spectrometry. Anal. Chem. 2006, 78, 3807-3814.

98. Song, L.; Bartmess, J. E. Liquid Chromatography/Negative Ion Atmospheric Pressure Photoionization Mass Spectrometry: A Highly Sensitive Method for the Analysis of Organic Explosives. Rapid Commun. Mass Spectrom. 2009, 23, 77-84.

99. Ifa, D. R.; Manicke, N. E.; Rusine, A. L.; Cooks, R. G. Quantitative Analysis of Small Molecules by Desorption Electrospray Ionization Mass Spectrometry from Polytetrafluoroethylene Surfaces. Rapid Commun. Mass Spectrom. 2008, 22, 503-510.

100. Luosujarvi, L.; Arvola, V.; Haapala, M.; Pol, J.; Saarela, V.; Franssila, S.; Kotiaho, T.; Kostiainen, R.; Kauppila, T. J. Desorption and Ionization Mechanisms in Desorption Atmospheric Pressure Photoionization. Anal. Chem. 2008, 80, 7460-7466.

101. Nyadong, L.; Late, S.; Green, M. D.; Banga, A.; Fernandez, F. M. Direct Quantitation of Active Ingredients in Solid Artesunate Antimalarials by Noncovalent Complex Forming Reactive Desorption Electrospray Ionization Mass Spectrometry. I. Am. Soc. Mass Spectrom. 2008, 19, 380-388

102. Nyadong, L.; Hohenstein, E. G.; Johnson, K.; Sherrill, C. D.; Green, M. D.; Fernandez, F. M. Desorption Electrospray Ionization Reactions Between Host Crown Ethers and the Influenza Neuraminidase Inhib- itor Oseltamivir for the Rapid Screening of Tamiflu (R). Analyst 2008, 133, 1513-1522.

103. Jackson, A. U.; Werner, S. R.; Talaty, N.; Song, Y.; Campbell, K.; Cooks, R. G.; Morgan, J. A. Targeted Metabolomic Analysis of Escherichia coli by Desorption Electrospray Ionization and Extractive Electrospray Ionization Mass Spectrometry. Anal. Biochem. 2008, 375, 272-281.

104. Jecklin, M. C.; Gamez, G.; Touboul, D.; Zenobi, R. Atmospheric Pressure Glow Discharge Desorption Mass Spectrometry for Rapid Screening of Pesticides in Food. Rapid Commun. Mass Spectrom. 2008, 22, 2791-2798

105. Gonzalez, M.; Miglioranza, K. S. B.; de Moreno, J. E. A.; Moreno, V. J. Occurrence and Distribution of Organochlorine Pesticides (OCPs) in Tomato (Lycopersicon Esculentum) Crops from Organic Production. J. Agric. Food. Chem. 2003, 51, 1353-1359.

106. Chen, H. W.; Liang, H. Z.; Ding, J. H.; Lai, J. H.; Huan, Y. F.; Qiao, X. L. Rapid Differentiation of Tea Products by Surface Desorption Atmospheric Pressure Chemical Ionization Mass Spectrometry. J. Agric. Food Chem. 2007, 55, 10093-10100.

107. Marquez, C. A.; Wang, H. Y.; Fabbretti, F.; Metzger, J. O. ElectronTransfer-Catalyzed Dimerization of trans-Anethole: Detection of the Distonic Tetramethylene Radical Cation Intermediate by Extractive Electrospray Ionization Mass Spectrometry. J. Am. Chem. Soc. 2008, 130, $17208-17209$.

108. Williams, J. P.; Scrivens, J. H. Coupling Desorption Electrospray Ionization and Neutral Desorption/Extractive Electrospray Ionization with a Traveling-Wave Based Ion Mobility Mass Spectrometer for the Analysis of Drugs. Rapid Commun. Mass Spectrom. 2008, 22, 187-196.

109. Nefliu, M.; Smith, J. N.; Venter, A.; Cooks, R. G. Internal Energy Distributions in Desorption Electrospray Ionization (DESI). J. Am. Soc. Mass Spectrom. 2008, 19, 420-427.

110. Venter, A.; Sojka, P. E.; Cooks, R. G. Droplet Dynamics and Ionization Mechanisms in Desorption Electrospray Ionization Mass Spectrometry. Anal. Chem. 2006, 78, 8549-8555.

111. Costa, A. B.; Cooks, R. G. Simulation of Atmospheric Transport and Droplet-Thin Film Collisions in Desorption Electrospray Ionization. Chem. Commun. 2007, 3915-3917.

112. Costa, A. B.; Cooks, R. G. Simulated Splashes: Elucidating the Mechanism of Desorption Electrospray Ionization Mass Spectrometry. Chem. Phys. Lett. 2008, 464, 1-8.

113. Bereman, M. S.; Muddiman, D. C. Detection of Attomole Amounts of Analyte by Desorption Electrospray Ionization Mass Spectrometry (DESI-MS) Determined Using Fluorescence Spectroscopy. J. Am. Soc. Mass Spectrom. 2007, 18, 1093-1096.

114. Volny, M.; Venter, A.; Smith, S. A.; Pazzi, M.; Cooks, R. G. Surface Effects and Electrochemical Cell Capacitance in Desorption Electrospray Ionization. Analyst 2008, 133, 525-531.

115. Haddad, R.; Sparrapan, R.; Eberlin, M. N. Desorption Sonic Spray Ionization for (High) Voltage-Free Ambient Mass Spectrometry. Rapid Commun. Mass Spectrom. 2006, 20, 2901-2905.

116. Haddad, R.; Sparrapan, R.; Kotiaho, T.; Eberlin, M. N. Easy Ambient Sonic-Spray Ionization-Membrane Interface Mass Spectrometry for Direct Analysis of Solution Constituents. Anal. Chem. 2008, 80, 898903.

117. McEwen, C. N.; McKay, R. G.; Larsen, B. S. Analysis of Solids, Liquids, and Biological Tissues Using Solids Probe Introduction at Atmospheric Pressure on Commercial LC/MS Instruments. Anal. Chem. 2005, 77, 7826-7831.

118. Nicol, G.; Sunner, J.; Kebarle, P. Kinetics and Thermodynamics of Protonation Reactions: $\mathrm{H}_{3} \mathrm{O}+\left(\mathrm{H}_{2} \mathrm{O}\right)_{\mathrm{h}}+\mathrm{B}=\mathrm{BH}+\left(\mathrm{H}_{2} \mathrm{O}\right)_{\mathrm{b}}+(\mathrm{h}-\mathrm{b}+$ 1) $\mathrm{H}_{2} \mathrm{O}$, Where $\mathrm{B}$ is a Nitrogen, Oxygen or Carbon Base. Int. J. Mass Spectrom. Ion Processes 1988, 84, 135-155.

119. Harris, G. A.; Fernandez, F. M. Simulations and Experimental Investigation of Atmospheric Transport in an Ambient Metastable-Induced Chemical Ionization Source. Anal. Chem. 2009, 81, 322-329.

120. Ratcliffe, L. V.; Rutten, F. J. M.; Barrett, D. A.; Whitmore, T.; Seymour, D.; Greenwood, C.; Aranda-Gonzalvo, Y.; Robinson, S.; McCoustra, M Surface Analysis Under Ambient Conditions Using Plasma-Assisted Desorption/Ionization Mass Spectrometry. Anal. Chem. 2007, 79, 60946101.

121. Andrade, F. J.; Shelley, J. T.; Wetzel, W. C.; Webb, M. R.; Gamez, G. Ray, S. J.; Hieftje, G. M. Atmospheric Pressure Chemical Ionization Source. 2. Desorption-Ionization for the Direct Analysis of Solid Compounds. Anal. Chem. 2008, 80, 2654-2663.

122. Stoffels, E.; Flikweert, A. J.; Stoffels, W. W.; Kroesen, G. M. W. Plasma Needle: A Nondestructive Atmospheric Plasma Source for Fine Surface Treatment of (Bio)Materials. Plasma Sources Sci. Technol. 2002, 11, 383-388

123. Andrade, F. J.; Wetzel, W. C.; Chan, G. C. Y.; Webb, M. R.; Gamez, G.; Ray, S. J.; Hieftje, G. M. A New, Versatile, Direct-Current Helium Atmospheric-Pressure Glow Discharge. J. Anal. At. Spectrom. 2006, 21 1175-1184.

124. Dzidic, I.; Carroll, D. I.; Stillwell, R. N.; Horning, E. C. Comparison of Positive Ions Formed in Nickel-63 and Corona Discharge Ion Sources, Using Nitrogen, Argon, Isobutane, Ammonia, and Nitric Oxide as Reagents in Atmospheric-Pressure Ionization Mass-Spectrometry. Anal. Chem. 1976, 48, 1763-1768.

125. Na, N.; Zhao, M.; Zhang, S.; Yang, C.; Zhang, X. Development of a Dielectric Barrier Discharge Ion Source for Ambient Mass Spectrometry. J. Am. Soc. Mass Spectrom. 2007, 18, 1859-1862. 
126. Shiea, J.; Huang, M. Z.; Hsu, H. J.; Lee, C. Y.; Yuan, C. H.; Beech, I.; Sunner, J. Electrospray-Assisted Laser Desorption/Ionization Mass Spectrometry for Direct Ambient Analysis of Solids. Rapid Commun. Mass Spectrom. 2005, 19, 3701-3704.

127. Nemes, P.; Vertes, A. Laser Ablation Electrospray Ionization for Atmospheric Pressure, In Vivo, and Imaging Mass Spectrometry. Anal. Chem. 2007, 79, 8098-8106.

128. Rezenom, Y. H.; Dong, J.; Murray, K. K. Infrared Laser-Assisted Desorption Electrospray Ionization Mass Spectrometry. Analyst 2008, $133,226-232$

129. Coon, J. J.; McHale, K. J.; Harrison, W. W. Atmospheric Pressure Laser Desorption/Chemical Ionization Mass Spectrometry: A New Ionization Method Based on Existing Themes. Rapid Commun. Mass Spectrom. 2002, 16, 681-685.

130. Coon, J. J.; Harrison, W. W. Laser Desorption-Atmospheric Pressure Chemical Ionization Mass Spectrometry for the Analysis of Peptides from Aqueous Solutions. Anal. Chem. 2002, 74, 5600-5605.

131. Jorabchi, K.; Westphall, M. S.; Smith, L. M. Charge Assisted Laser Desorption/Ionization Mass Spectrometry of Droplets. J. Am. Soc. Mass Spectrom. 2008, 19, 833-840.

132. Westphall, M. S.; Jorabchi, K.; Smith, L. M. Mass Spectrometry of Acoustically Levitated Droplets. Anal. Chem. 2008, 80, 5847-5853.

133. Shelley, J. T.; Ray, S. J.; Hieftje, G. M. Laser Ablation Coupled to a Flowing Atmospheric Pressure Afterglow for Ambient Mass Spectral Imaging. Anal. Chem. 2008, 80, 8308-8313.
134. Chang, D. Y.; Lee, C. C.; Shiea, J. Detecting Large Biomolecules from High-Salt Solutions by Fused-Droplet Electrospray Ionization Mass Spectrometry. Anal. Chem. 2002, 74, 2465-2469.

135. Dixon, R. B.; Sampson, J. S.; Muddiman, D. C. Generation of Multiply Charged Peptides and Proteins by Radio Frequency Acoustic Desorption and Ionization for Mass Spectrometric Detection. J. Am. Soc. Mass Spectrom. 2009, 20, 597-600.

136. Ifa, D. R.; Jackson, A. U.; Paglia, G; Cooks, R. G. Forensic Applications of Ambient Ionization Mass Spectrometry. Anal. Bioanal. Chem. 2009, 394, 1995-2008.

137. Martinez-Lozano, P.; Rus, J.; de la Mora, G. F.; Hernandez, M.; Fernandez de la Mora, J. Secondary Electrospray Ionization (SESI) of Ambient Vapors for Explosive Detection at Concentrations Below Parts Per Trillion. J. Am. Soc. Mass Spectrom. 2009, 20, 287-294.

138. Chen, H. W.; Zenobi, R. Direct Analysis of Living Objects by Extractive Electrospray Mass Ionization Spectrometry. Chimia 2007 $61,843$.

139. Johnson, G. R.; Morawska, L. The Mechanism of Breath Aerosol Formation. J. Aerosol Med. Pulm. Drug Deliv. 2009, 22, 1-9.

140. Shieh, I. F.; Lee, C. Y.; Shiea, J. Eliminating the Interferences from TRIS Buffer and SDS in Protein Analysis by Fused-Droplet Electrospray Ionization Mass Spectrometry. J. Proteome Res. 2005, 4, 606612.

141. Willoughby, R. C. Method and Apparatus for Increased Electrospray Ion Production, U.S. Patent no. 2000,6,147,345. 